\title{
PARALISIAS MÚLTIPLAS DE NERVOS ENCEFÁLICOS PRODUZIDAS POR NEOPLASIAS DA BASE DO CRÂNIO
}

\author{
Horacio M. Canelas * \\ Oswaldo Freitas Julião*
}

Os tumores da base do crânio, quer primitivamente intracranianos, quer provenientes da nasofaringe ou de outras origens extracranianas, constituem importante capítulo da neuropatologia, não só pela gravidade dos quadros que se estabelecem, como pelo freqüente atraso com que são reconhecidas, e ainda pelas questões diagnósticas que podem levantar.

Mesmo nos tumores de origem extracraniana, as primeiras manifestações podem consistir em distúrbios neurológicos, o que poderá desorientar o clínico, fazendo-o pensar em processos de outra etiologia. O êrro se fundamenta no fato de que, freqüentemente, tais tipos de neoplasia não determinam sinais de hipertensão intracraniana, o que levaria a afastar a etiologia tumoral. Outro fator de confusão reside em que o próprio estudo radiológico, em fases relativamente precoces do processo neoplásico, pode não revelar as alterações que seriam de esperar.

Os tumores primitivos ou secundários da base do crânio caracterizam-se, do ponto de vista neurológico, por comprometimento dos nervos cranianos. Nas neoplasias primitivamente intracranianas não há, habitualmente, sistematização quanto às paralisias, que se associam de variada forma, segundo a topografia inicial do blastoma. Nos tumores de origem extracraniana, porém, a invasão da base, através de aberturas naturais ou de erosões patológicas, se faz em geral na fossa média, compreendendo-se, assim, que os nervos inicialmente atingidos sejam os motores oculares e o trigêmeo; configura-se, dessa maneira, muitas vêzes, uma síndrome de Jacod ${ }^{56}$, que progressivamente se enriquece, a ponto de, eventualmente, verificar-se o comprometimento unilateral de todos os nervos cranianos.

Além do caráter progressivo com que as paralisias se sucedem, há um dado de grande importância diagnóstica, que é a unilateralidade habitualmente apresentada por essas sindromes.

Não nos preocuparemos com as numerosas sindromes parciais de comprometimento associado de nervos cranianos que, de regra, constituem meros

Trabalho da Clinica Neurológica (Prof. Adherbal Tolosa) da Faculdade de Medicina da Universidade de Sāo Paulo: * Assistente-Docente. 
instantâneos da evolução do processo neoplásico. A meta final será o estabelecimento de uma síndrome paralítica global, que, por ter sido esmiuçada e valorizada por Garcin ${ }^{41}$, lhe deve com propriedade a eponimia.

Valendo-nos da oportunidade que tivemos de observar 10 casos de paralisias múltiplas, unilaterais, de nervos cranianos, julgamos de interêsse apresentá-los, mesmo porque são ainda escassas as publicações brasileiras versando êste tema. Numa revisão da literatura nacional, pelo que pudemos apurar, apenas computamos os casos registrados por Clark 26 (1929), Linneu Silva e col.118 (1930), Toledo e Gama ${ }^{124}$ (1938), Osório ${ }^{90}$ (1947), Aprigliano $^{5}$ (1947), Aboab e col. ${ }^{1}$ (1954), Cruz e Tenuto ${ }^{32}$ (1959) e Rezende Barbosa e col.99 (1959).

Na literatura estrangeira são numerosos os trabalhos sôbre o assunto, sendo a maioria representada por contribuições sôbre os tumores malignos da nasofaringe.

O estudo destas neoplasias iniciou-se em 1837, com o caso descrito por Durand-Fardel ${ }^{35}$. A invasão do crânio, entretanto, só foi registrada em 1859, num caso de câncer faringeo referido por Lotzbeck (cit. por Jackson ${ }^{54}$ ). Schweich ${ }^{115}$ e Verneuil (cit. por Woltman ${ }^{136}$ ), em 1867, relataram a existência de paralisias de nervos cranianos produzidas por sarcoma basilar. Em 1873, Flour 38 registrou o primeiro caso de carcinoma da rinofaringe com sintomatologia neurológica. Em 1901, Escat ${ }^{36}$ ressaltou a precocidade da neuralgia facial nessas eventualidades. Laval 65 (1904) sistematizou as formas clínicas e evolutivas dessas neoplasias. Em 1913, Oppikofer ${ }^{88}$ já conseguiu computar 250 casos de tumores rinofaringeos registrados na literatura e descreveu 21 casos, incluindo 15 com estudo necroscópico, 8 dos quais apresentavam distúrbios neurológicos; Oppikofer salientou a ocorrência precoce de enfartamentos de gânglios cervicais, de sintomas auditivos por obstrução tubária e de comprometimento de nervos cranianos, assim como a ausência de sinais de hipertensão intracraniana e a preservação da dura mater, que seria responsável pela habitual ausência de sinais de lesão encefálica. Em 1922, Woltman ${ }^{13 ;}$ estudou particularmente as lesões neurológicas determinadas por essas neoplasias, realçando a precocidade com que se instalam as paralisias de nervos cranianos, o que poderá levar à idéia errônea de lesão primitivamente intracraniana.

Needles ${ }^{84}$, em 1937, estudou o componente neurológico da sintomatologia dos tumores da rinofaringe e, além de dar o justo valor às contribuições pioneiras de Escat ${ }^{36}$ e Oppikofer ${ }^{88}$, fêz um estudo minucioso de vários aspectos fundamentais do problema. Em 1944, Godtfredsen ${ }^{44}$ reviu pormenorizadamente a literatura e, baseado em 454 casos de neoplasias da rinofaringe recolhidos em Serviços dinamarqueses e suecos, estudou aprofundadamente a histopatologia, o quadro clínico e o tratamento dêsses blastomas; note-se que, de 172 casos com manifestações neuroftalmológicas, apenas 4 apresentavam paralisias múltiplas (sete ou mais nervos) de pares cranianos.

Pela expressiva casuística merecem referência especial os trabalhos de Simmons e Ariel 119, Mekie e Lawley ${ }^{77}$, Scevola ${ }^{114}$, Martin e Blady 74, Molony ${ }^{80}$, Kasabach ${ }^{58}$, Furstenberg ${ }^{40}$, Zuppinger ${ }^{138}$, Salinger e Pearlman ${ }^{113}$, 
Bartels ${ }^{13}$, e particularmente os de Oya e Segovia ${ }^{91}$, Orbán ${ }^{89}$, Rosenbaum e Seaman ${ }^{111}$, Insausti e col. ${ }^{53}$, Arana fñiguez e col. ${ }^{6}$, Riggs e col. ${ }^{102}$, Henson e col. ${ }^{51}$, Weiss ${ }^{132}$, Romay e Blumtritt ${ }^{108}$, Asenjo e col. ${ }^{7}$ e Babonneix e Sigwald ${ }^{11}$, em que as manifestações neurológicas foram estudadas com mais minúcias. Além dêsses trabalhos sobressaem os registros de casos de síndrome paralítica global de nervos cranianos, de autoria de Pardal ${ }^{95}$, Paviot e col.97, Charleux e col. ${ }^{23}$, Léchelle e col. ${ }^{36}$, André-Thomas ${ }^{4}$, Monier-Vinard e Brunel ${ }^{81}$, Staffieri e col. ${ }^{122}$, Martinez e Levit ${ }^{75}$, Montanaro e col. ${ }^{82}$, VotoBernales e col.131, Baasch ${ }^{10}$, Coulliaud-Maisonneuve e Mondzain ${ }^{30}$, Lafon e col. ${ }^{62}$.

Em 1927, após ter registrado dois casos pessoais 47, 135, Garcin publicou sua tese 41 sôbre as paralisias unilaterais globais dos nervos cranianos, na qual reviveu o assunto sob novos ângulos e, baseado em observaçōes pessoais e em outras recolhidas na literatura, estabeleceu um marco fundamental na história dessas síndromes. Além de realçar o valor do exame radiológico, coube a Garcin o mérito de valorizar os seguintes dados para o diagnóstico: a) unilateralidade das paralisias; b) extensão a todos os nervos cranianos; c) ausência de sinais de hipertensão intracraniana; d) inexistência de sinais de comprometimento do sistema nervoso central.

\section{CASUISTICA PESSOAL}

CASo 1 - Sindrome paralitica global dos nervos cranianos, à direita. Alterações radiológicas da base do crânio. Tumor da rinofaringe e conduto auditivo externo, à direita. Biopsia da neoplasia: sarcoma mixoblástico.

V.J., com 10 anos de idade, pardo, brasileiro, examinado na Clínica Neuroiógica em 3-10-1946 (reg. HC 048250). A moléstia principiou a manifestar-se há 40 dias, aproximadamente, com desvio do ôlho direito para dentro; pouco tempo depois, dores no ouvido direito e na garganta, dificuldade na movimentação da língua e na deglutição, desvio da bôca para a esquerda. Há 15 dias, queda da pálpebra superior direita. Tonturas, especialmente no periodo matinal. Ültimamente, ligeiras dores na região frontal direita e face ipsolateral do pescoço. Disfonia. Não há refluxo de alimentos pelo nariz. Nega cefaléia e vômitos. Exame clínico - Adenopatia infra-auricular, à direita. Abaulamento do hemipalato mole direito por tumor da nasofaringe, de superficie irregular. Conduto auditivo direito cheio de tecido vegetante, de superficie granulosa e sangrante. O exame do aparelho cárdiorespiratório é normal. Fígado palpável a um dedo abaixo do rebordo costal, indolor.

Exame neurológico - Não há alterações quanto aos membros: motilidade, sensibilidades e reflexos normais. Nervos cranianos (figs. 1 e 2): Anosmia à direita. Acuidade visual: 0,2 à direita e normal à esquerda. Leve congestão venosa das papilas. Ptose palpebral, oftalmoplegia total, midriase e arreflexia pupilar, à direita. Sensibilidade superficial muito comprometida na hemiface direita; arreflexia corneana đêste lado. Paralisia do masseter e temporal direitos. Paralisia facial, tipo periférico, com reação de degenerescência total dêsse nervo e de seu território muscular, à direita. Dêste lado, ageusia nos dois terços anteriores da língua. Hipoacusia, tipo condução, à direita; hiporreflexia vestibular à prova rotatória. Paralisia da hemifaringe direita, com ageusia no têrço posterior da língua. Paralisia do véu e da corda vocal, à direita; disfagia e disfonia. Hipotonia e comprometimento da motilidade e troficidade dos músculos esternoclidomastóideo e trapézio direitos; sindrome elétrica de degeneração parcial nesses músculos. Comprometimento da motilidade, fasciculações e atrofia da hemilingua direita. 
Exames complementares - Liqüido cefalorraqueano (punção suboccipital): pressão inicial 20; limpido e incolor; ausência de alterações quimicas ou biológicas. Craniograma: tumor da região craniofaringea direita, destruindo $o$ andar médio do crânio, à direita, numa extensa zona que abrange a pequena asa do esfenóide, o fundo da órbita, os forames redondo, oval e espinhoso, a ponta da pirâmide, o conduto auditivo interno e o contôrno anterior do forame jugular; o tumor invade também os seios etmoidal e esfenoidal direitos; erosão da parede anterior do conduto auditivo externo e do rebordo inferior da arcada zigomática. Biopsia da massa tumoral da nasofaringe $e$ do conduto auditivo: sarcoma mixoblástico.

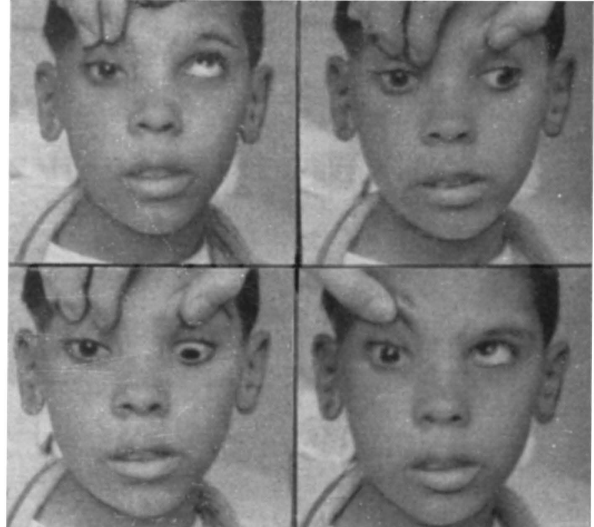

Fig. 1 - Caso 1: oftalmoplegia completa $\grave{a}$ direita.

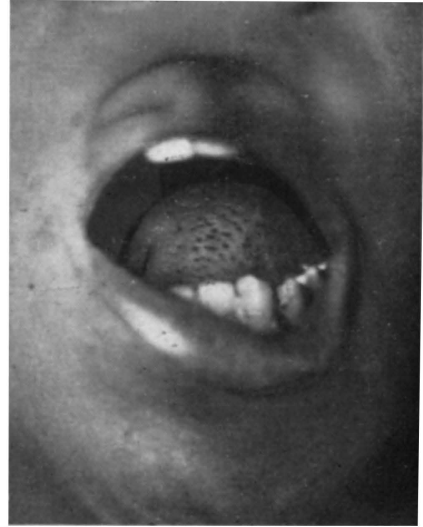

Fig. 2 - Caso 1: à direita, paralisia facial e paralisia amiotrófica da hemilíngua.

CASo 2 - Síndrome paralitica dos nervos cranianos $I I I$ a XII, à direita. Alterações radiológicas da base craniana. Tumor da rinofaringe e conduto auditivo externo, à direita. Necropsia: carcinoma planocelular sólido.

J.C., com 57 anos de idade, prêto, norte-americano, internado na Clínica Neurológica em 31-7-1946 (reg. HC 032408). Em junho 1945 o paciente começou a apresentar cefaléia ocasional, desacompanhada de vômitos; nesse estado manteve-se até novembro, quando surgiu, sùbitamente, estrabismo divergente no ôlho direito. Quase na mesma época, começou a sentir dores no ouvido direito, notando ainda baixa progressiva da acuidade auditiva nesse lado; submeteu-se, em principios de 1946, a mastoidectomia. A cefaléia continuou a manifestar-se nos meses seguintes, sempre desacompanhada de vômitos. O estrabismo regrediu ao fim de algum tempo. Há cêrca de 5 meses submeteu-se a exame otorrinolaringológico, que demonstrou a existéncia de tumor da nasofaringe; fêz, então, uma série de aplicaçōes de radioterapia. Há 2 meses notou que a bôca se apresentava repuxada para a esquerda e que a pálpebra superior direita estava caída, não conseguindo também movimentar o globo ocular direito. A articulação da palavra tornou-se difícil e surgiram distúrbios da deglutição. A gustação já vinha comprometida há algum tempo. Tem tido, ùltimamente, dores na hemiface e ouvido direitos, assim como nos membros dêsse lado. Exame clinico - Mau estado geral. Gânglios: apenas os ingüinais são palpáveis. Irregularidade da mucosa na parede lateral direita da rinofaringe (onde foi feita biopsia, há meses). Fundo do conduto auditivo direito cheio de granulação vegetante e hemorrágica. 
Exame neurológico - Discreto embotamento psiquico. Nos membros, a motiljdade voluntária encontra-se conservada, embora a fôrça muscular esteja diminuída de modo geral; coordenação cinética e tono muscular normais; marcha um tanto incerta, com pequeno alargamento da base de sustentação. Reflexos aquileus ausentes, patelares e abdominais diminuidos; normais os restantes. Sensibilidade objetiva conservada. Ligeira hiperestesia nos membros direitos. Nervos cranianos: Exoftalmo à direita; opacidade do cristalino de ambos os olhos, impossibilitando o exame dos fundos oculares. Oftalmoplegia total à direita (ptose palpebral, imobilidade do globular ocular e midriase). Dores e hiperestesia na hemiface direita; reflexo corneano presente; motilidade dos músculos mastigadores conservada; ao Exame elétrico, tendência à contração lenta no temporal direito. Paralisia facial à direita, com sindrome elétrica de degeneração parcial; ageusia na metade direita dos dois terços anteriores da lingua. Surdez à direita; arreflexia vestibular ipsolateral. Reflexo faríngeo abolido pelas excitações à direita; disgeusia no têrço posterior da hemilingua direita. Paralisia do véu direito; disfagia. Hipotonia discreta do esternoclidomastóideo e trapézio à direita; ao exame elétrico, igualdade polar no esternoclidomastóideo direito. Paresia, hipotonia e fasciculações da hemilíngua direita.

Exames complementares - Craniograma: amputação do ápice da pirâmide direita, de tipo erosivo, incluindo o meato acústico interno; erosão do soalho da fossa média, de limites imprecisos; sela turca e mastóides normais; ausência de sinais de hipertensão ou calcificações patológicas. Liqüido cefalorraqueano (punção suboccipital): pressão inicial 10; límpido e incolor; 17,4 células $/ \mathrm{mm}^{3}$ (linfocitose); proteinas $15 \mathrm{mg} / 100 \mathrm{ml}$; reações de Pandy e Nonne levemente positivas; outras reaçōes normais. Biopsia da massa tumoral da nasofaringe e do ouvido: carcinoma sólido.

Evolução - O paciente piorou progressivamente, entrando em caquexia. Faleceu em 16-9-1946. Necropsia (SS 23568/46, Dr. José Lopes de Faria): Abaulamento discreto e irregular da base do crânio, ả direita, desde o ápice da órbita até o forame jugular; a região é recoberta pela dura mater, espessada em algumas áreas e apresentando saliências com aspecto papilomatoso. Os nervos cranianos VII a XII, no segmento intracraniano, apresentam-se comprometidos pelo tumor. Um corte sagital mediano da base do crânio mostra tecido de côr esbranquiçada, de textura frouxa, friável, invadindo a sela turca e lâmina quadrilátera, chegando até o rebordo anterior do forame occipital. Leptomeninge ligeiramente espessada. Troncos arteriais da base com ateromatose. A face orbitária do lobo frontal direito apresenta extensa área de amolecimento, interessando o córtex e a porção imediatamente próxima da substância branca; o mesmo se observa do lado esquerdo, porém, aqui a área de amolecimento é pequena e destrói apenas a substância branca. Nos cortes frontais observa-se discreta congestão vascular em todo o cérebro, ligeira dilatação dos ventrículos laterais e do terceiro. No rombencéfalo, massa de tecido neoplásico aderente à leptomeninge que recobre o flóculo cerebelar direito. o restante da autópsia revelou, de interêsse, hipertrofia dos gânglios linfáticos retrofaríngeos superiores e infiltração carcinomatosa do nasofaringe, com inflamação crônica fibrosante. Diagnóstico histopatológico do tumor da base craniana: carcinoma planocelular, de células intermediárias, sólido.

CASo 3 - Sindrome paralitica global dos nervos cranianos à direita (II ao $X I I)$. Tumor da região parotidea direita. Ao exame radiológico, áreas de osteólise na abóbada e base cranianas e nódulo no campo pulmonar direito. Metástases ganglionares. Necropsia: carcinoma sólido da base do crânio.

M.A.M., com 48 anos de idade, branca, brasileira, internada na Clínica Neurológica em 30-1-1961 (reg. HC 601350). Em novembro 1959 a paciente notou o aparecimento de tumoração na região pré-auricular direita, dolorosa, sem rubor ou calor. Decorridos 15 dias, instalou-se paralisia facial direita. Em junho 1960 passou a apresentar disfagia e voz analasada. De 5-10-60 a 4-11-60 estêve internada 
em outro Serviço de Neurologia (Escola Paulista de Medicina), onde foi verificada a existência de paralisia do $\mathrm{V}$ ao XI nervos cranianos direitos; a tumoração da região parotidea apresentava, então, sinais inflamatórios; o exame do liqüido cefalorraqueano revelou, de anormal, apenas 9 células $/ \mathrm{mm}^{3}$ (linfomononucleares); o craniograma mostrou velamento dos orifícios da fossa média; a pneumocisternografia não evidenciou anormalidades das cisternas pré-pontina, interpeduncular e ambiens. A tumoração foi incisada, drenando pus, e a paciente foi tratada com antibióticos. Em dezembro 1960 manifestaram-se ptose palpebral e diminuição da acuidade visual à direita. Exame clínico - Paciente em mau estado geral. Tumoração na região parotídea direita. Dois nódulos moles, indolores, nas regiões frontal e temporal direitas; três gânglios retro-auriculares à direita e um à esquerda; um gânglio supraclavicular à direita.

Exame neurológico - Ausência de distúrbios motores, sensitivos ou da coordenação cinética no tronco e membros. Nervos cranianos (fig. 3): À direita, sinaís de lesão dos nervos II a XII. Amaurose total; papila homogêneamente pálida. Oftalmoplegia total, intrinseca e extrinseca. Anestesia na hemiface e córnea; reflexo corneopalpebral abolido; paralisia dos músculos mastigadores, com atrofia do temporal. Paralisia facial de tipo periférico; hipogeusia nos dois tercos anteriores

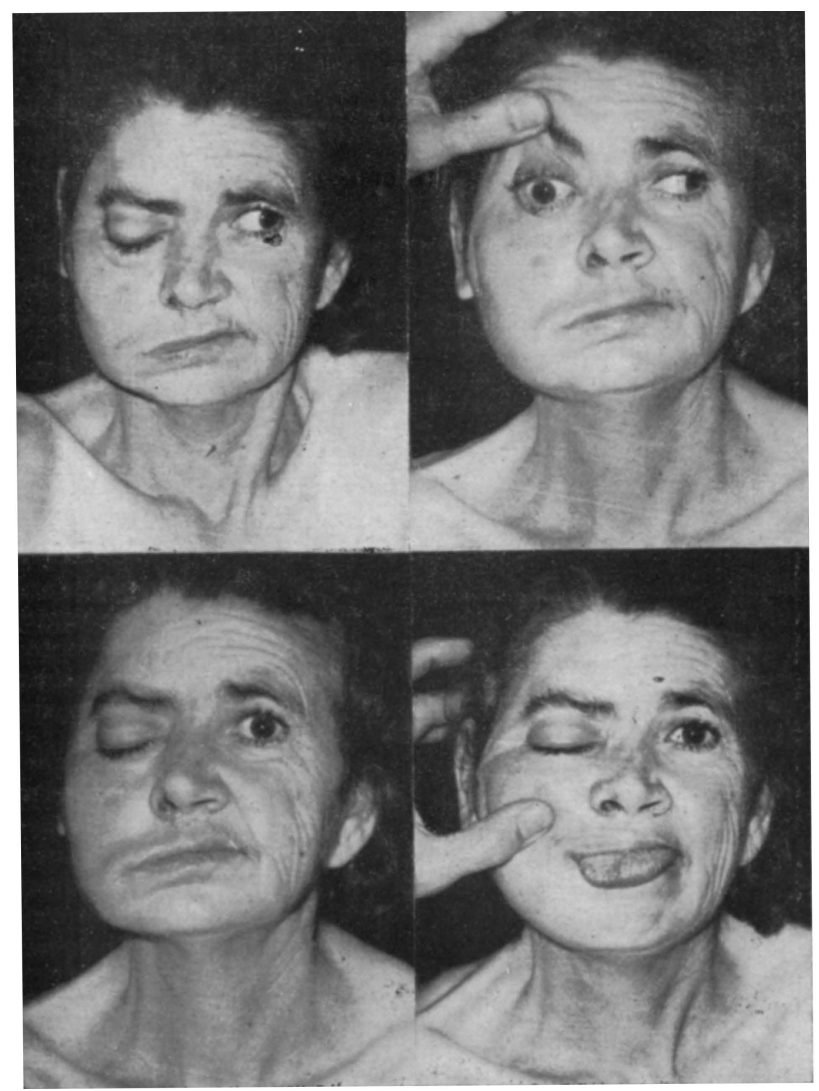

Fig. 3 - Caso 3: à direita, oftalmoplegia, paralisia facial, paralisia do nervo acessório espinal e paresia do hipoglosso. 
da hemilíngua. Acentuada hipoacusia; arreflexia vestibular. Paralisia velofaringea. Paralisia dos músculos esternoclidomastóideo e trapézio. Hemilíngua atrófica, desviando-se para a direita na protrusāo. A esquerda, apenas hipoestesia na hemiface, sendo normais a sensibilidade corneana e o reflexo corneopalpebral.

Exames complementares - Craniograma: grandes focos de osteólise nas regiões frontal e parietotemporal direitas; destruição do soalho selar e do clivus; extenso processo osteolitico da ponta e porção proximal da pirâmide direita (sinais de metástases osteoliticas); na posição de Hirtz observa-se invasão do crânio pelo tumor, determinando velamento dos seios esfenoidais. Carótido-angiografia direita: artéria cerebral média deslocada para cima, seguindo trajeto sinuoso; a. cerebral anterior delgada desde sua origem, com trajeto sensivelmente normal; não há sinais de circulação patológica; quadro de processo expansivo subtemporal. Radiografia do tórax: nódulo no campo pulmonar médio direito. Eletrencefalograma: dentro dos limites da normalidade. Líqüido cefalorraqueano (punção suboccipital): pressāo inicial 12; límpido e incolor; 2 células $/ \mathrm{mm}^{3}$; proteínas $53 \mathrm{mg} / 100 \mathrm{ml}$; reação do benjoim 01111.22221.00000.0; reações de Pandy e Nonne positivas; outras reações, normais. Eletrodiagnóstico: reação de degeneração completa no nervo facial e nos territórios dos músculos frontal, temporal, trapézio, esternoclidomastóideo e da hemilingua, à direita. Biopsia da tumoração da região parotídea: adenocarcinoma infiltrado em tecido conjuntivo fibroso (a lesão pode ser conseqüente a um tumor misto de glândula salivar com evolução maligna).

Evolução - A paciente piorou progressivamente. A cobaltoterapia foi considerada inútil devido ao avançado grau de desenvolvimento da neoplasia e à existência de metástases difusas. Obito em 20-6-1961. Necropsia (SS 57859/61, Dr. Mario Rubens Montenegro): Retirado o encéfalo, observa-se grande massa tumoral que, destruindo os ossos da fossa média, faz saliência para dentro da cavidade craniana. O tecido tumoral é branco, opaco, de consistência firme, contendo pequenas áreas de necrose; èle respeita a dura mater, com exceção de pequena área correspondente ao pólo temporal direito; na sela turca, empurra e, ao que parece, infiltra a hipófise; crescendo para a cavidade orbitária direita, desloca o globo ocular para a frente. Cortes realizados ao nível da sela turca, corpo do esfenóide e retrofaringe mostram uma neoplasia constituida por massas epiteliais sólidas, contidas em abundante estroma conjuntivo. Em alguns pontos as massas parecem formar luzes, porém, trata-se de necrose central amolecida. Notam-se, ainda, extensas áreas de necrose. Diagnóstico histopatológico: carcinoma sólido. Dentre os restantes achados necroscópicos, ressalta a existência de metástases nos pulmões e nos gânglios submandibulares.

CASo 4 - Síndrome paralítica dos nervos cranianos III a XI, à esquerda. Alterações radiológicas da base craniana. Biopsia ganglionar: carcinoma sólido metastático.

R.P., com 59 anos de idade, branco, brasileiro, internado na Clinica Neurológica em 11-6-1957 (reg. HC 475324). Há cêrca de um ano começou a sentir dores no hemicrânio esquerdo, que se estenderam, há 4 ou 5 meses, à hemiface correspondente; a principio intermitentes, as dores se tornaram, uiteriormente, continuas e rebeldes à medicação habitual. Algum tempo após o início da sintomatologia dolorosa manifestaram-se, no ouvido esquerdo, zumbidos e hipoacusia. Há 4 meses, dificuldade para articular as palavras e deglutir alimentos sólidos; abundante sialorréia. Há 3 meses, alterou-se a gustação na hemilingua esquerda. Há 2 meses, ptose palpebral à esquerda. Nos antecedentes, há apenas a referir diminuiçāo da acuidade visual à direita, notada desde a infância; obstrução nasal, instalada há muito; epistaxes ocasionais. Exame clínico - Gânglios submaxilares, pré e retrosternoclidomastóideos e no ângulo da mandibula. O exame otorrinolaringológico não mostrou abaulamentos ou tumoraçōes na rinofaringe; abundante secreção catarral nas fossas nasais; discreta hiperemia do timpano esquerdo. 
Exame neurológico - Nada de particular em relaçāo aos membros: motilidade, coordenação cinética, sensibilidade e reflexos normais. Nervos cranianos (fig. 4): Anosmia bilateral. Acuidade visual menor que 0,1 à direita, motivada por placa de coriorretinite atrófica macular; papilas normais. Oftalmoplegia total à esquerda, com midríase e arreflexia pupilar. Hipoestesia tátil, térmica e dolorosa em tôda a hemiface esquerda; dêste lado, arreflexia corneana; hipotrofia do masseter, à esquerda. Paresia facial, tipo periférico, à esquerda; ageusia nos dois terços an-

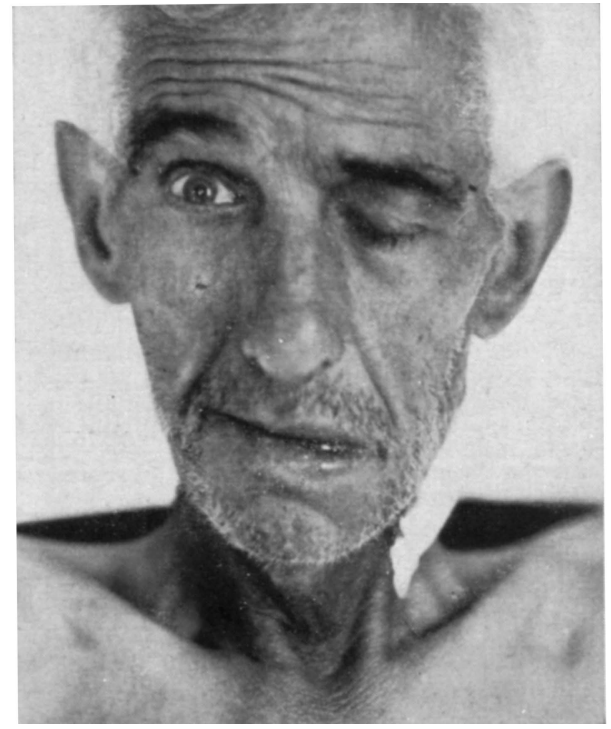

Fig. 4 - Caso 4: ptose palpebral e paralisia facial à esquerda. teriores da hemilíngua esquerda. Hipoacusia de condução bilateral, mais acentuada à esquerda; inexcitabilidade vestibular à esquerda e hipoexcitabilidade à direita. Paralisia do hemivéu esquerdo; disfagia para alimentos sólidos; discreta queda da epiglote; acúmulo de secreção catarral na laringe, dificultando o exame (tem-se a impressão de paralisia da corda vocal esquerda). Paresia e atrofia dos músculos esternoclidomastóideo e trapézio esquerdos. Desvio da língua para a direita, quando projetada fora da bôca.

Exames complementares - Craniograma: neoformação vegetante $\mathrm{e}$ expansiva da fossa média, com lesão osteolitica da ponta do rochedo esquerdo e do dorso selar no seu têrço posterior. Eletrencefalograma: normal. Liqüido cefalorraqueano (punção suboccipital): pressão inicial 10; límpido e incolor; 1 célula $/ \mathrm{mm}^{3}$; proteínas $29 \mathrm{mg} / 100 \mathrm{ml}$; reaçōes de Pandy e Nonne levemente positivas; outras reações normais. Biopsia de gânglio laterocervical esquerdo: carcinoma sólido metastático.

CASo 5 - Sindrome paralitica unilateral (esquerda) de nervos cranianos ( $V$ ao XII). Alteraçōes radiológicas, de tipo destrutivo, da fossa cerebral média. Biopsia ganglionar: carcinoma planocelular metastático.

V.B., com 17 anos de idade, branco, brasileiro, admitido na Clínica Otorrinolaringológica em 20-10-1950 (reg. HC 199602). Há 8 meses, dores na hemiface e hemicrânio esquerdos; otalgia ipsolateral; diplopia. Exame clinico - Adenopatia cervical bilateral. Ausência de processo tumoral na rinofaringe.

Exame neurológico - Ausência de distúrbios motores, sensitivos ou da coordenação cinética nos membros. Nervos cranianos: ligeira anisocoria (pupila esquerda menor). Acuidade visual e fundos oculares normais. Paralisia do abducente à esquerda. Ligeira hipoacusia de tipo misto, à esquerda; arreflexia vestibular bilateral à prova calórica; normorreflexia à prova rotatória. Paresia da orofaringe e paralisia velopalatina à esquerda. Hipotrofia do esternoclidomastóideo e do trapézio à esquerda. Paralisia da hemilingua esquerda.

Exames complementares - Craniograma: processo destrutivo do dorso e soalho selares, com penetração no seio esfenoidal; alteração destrutiva da fossa média. Liqüido cefalorraqueano (punçāo suboccipital): pressão inicial 15; límpido e incolor; 60 células $/ \mathrm{mm}^{3}$ (linfomononucleares); proteínas $20 \mathrm{mg} / 100 \mathrm{ml}$; reaçoes de Pandy e 
Nonne levemente positivas; outras reaçōes normais. Biopsia de gânglio da região cervical: carcinoma planocelular metastático.

CAso 6 - Oftalmoplegia total e comprometimento do trigêmeo à esquerda. Tumor do cavum. Biopsia da neoplasia: linfossarcoma.

H.T.M., com 5 anos de idade, branco, brasileiro, admitido na Clínica Otorrinolaringológica em 5-12-1959 (reg. HC 574278). Há 2 meses o paciente estêve "resfriado" e, desde então, vem tendo cefaléia frontal e otalgia, ả esquerda. Há 3 dias, ptose palpebral à esquerda. Adinamia e emagrecimento pronunciado. Exame otorrinolaringológico - Abaulamento do hemipalato esquerdo, com desvio da úvula para o lado oposto; posteriormente, e fazendo corpo com o palato mole, nota-se a existência de massa tumoral.

Exame neurológico - Ausência de distúrbios motores, sensitivos ou da coordenação cinética nos membros. Nervos cranianos: ptose palpebral e grande limitação de todos os movimentos oculares à esquerda; pupilas isocóricas, reagindo normalmente; fundos oculares normais. Comprometimento dos contingentes sensitivo e motor do trigèmeo à esquerda.

Exames complementares - Craniograma: acentuado espessamento da mucosa do antro maxilar esquerdo; ausência de-hipertensão intracraniana. Liqüido cefalorraqueano (punção suboccipital): normal. Biopsia da massa tumoral do cavum: linfossarcoma.

CAso 7 - Paralisia múltipla de nervos cranianos, à direita (VIII ao XII) $e$ sindrome de Claude Bernard-Horner ipsolateral. Alteraçōes radiológicas da base craniana. Tumor da nasofaringe. Biopsia da neoplasia: linfepitelioma.

G.P., com 22 anos de idade, pardo, brasileiro, admitido na Clínica Otorrinolaringológica em 10-12-1953 (reg. HC 351632). Há 6 meses, diminuição da acuidade auditiva à direita e, ulteriormente, dificuldade para falar e mastigar. Exame clinico - Adenopatia retromandibular à direita. Pela rinoscopia foi notado abaulamento da parede posterior da rinofaringe à direita.

Exame neurológico - Não há distúrbios motores, sensitivos ou da coordenação cinética nos membros. Nervos cranianos: Síndrome de Claude Bernard-Horner à direita. Limitação do abaixamento da mandibula. Hipoacusia à direita. Paralisia velofaringolaríngea à direita. Paresia e atrofia do esternoclidomastóideo e do trapézio, à direita. Paresia e alterações da excitabilidade elétrica neuromuscular na hemilingua direita.

Exames complementares - Craniograma: extensa erosão do soalho da fossa craniana média. Líqüido cefalorraqueano (punção suboccipital): normal. Biopsia da massa tumoral da nasofaringe: linfepitelioma.

Caso 8 - Sindrome paralitica unilateral esquerda de nervos cranianos (V, VII, $V I I I, I X, X$ e XI) evoluindo há 15 anos. Tumor no conduto auditivo externo. Ao exame radiológico, processo osteolítico da pirámide petrosa esquerda. Biopsia da neoplasia do conduto auditivo externo: tumor glômico.

L.B., com 53 anos de idade, branco, argentino, internado na Clínica Neurológica em 5-3-1960 (reg. HC 580316). Há 15 anos, por ocasião de um "resfriado", sentiu dores no ouvido esquerdo, que se irradiavam para as regiōes orbitária e maxilar do mesmo lado, acompanhadas de zumbidos e surdez. As dores cessaram ao fim de alguns dias; contudo, 5 meses após, reapareceram no globo ocular esquerdo, de modo transitório. Nessa ocasião estabeleceu-se desvio da bôca para a direita. Há 7 anos, notou dificuldade na elevação do ombro esquerdo. Há 4 anos, dores intensas na hemiface e ouvido esquerdos, ocorrendo sob a forma de crises despertadas 
pela mastigação, fala, "golpes de ar frio" ou manifestando-se espontâneamente. Os zumbidos e a surdez, à esquerda, persistem desde o início da moléstia. Refere - paciente que, estando sentado, percebe no ouvido esquerdo ruído comparável a escape de vapor, o qual desaparece nas posições extremas da cabeça (flexāo, extensão ou rotação), assim como pela compressão digital de uma ou de ambas as carótidas. Nos antecedentes, há referência a traumatismo ocular à direita, aos 12 anos, que determinou perda da visão dêsse lado. Exame clínico _. Bom estado geral; gânglios não aumentados de volume. A ausculta, sôpro sístólico intenso no trajeto da carótida esquerda, acentuando-se ao nivel das porções superiores da artéria até a mandibula; o mesmo sôpro é audivel na região retro-auricular esquerda, em sua porção inferior; desaparece pela compressão das carótidas; a compressão da carótida direita determina, após cêrca de 20 segundos, mal-estar, sensação vertiginosa, palidez e parestesias no hemicorpo esquerdo. O exame do ouvido esquerdo revela a existência de massa tumoral obstruindo totalmente os três quartos internos do conduto auditivo.

Exame neurológico — Não há, em relação aos membros, alterações merecedoras de registro. Durante a marcha o paciente apresenta, às vêzes, tendência a desvios para a esquerda e mantém a cabeça relativamente imobilizada. Nervos cranianos: Comprometimento acentuado da olfação, bilateralmente. Coroidite atrófica (póstraumática), à direita, com perda quase total da visão; à esquerda, fundo ocular

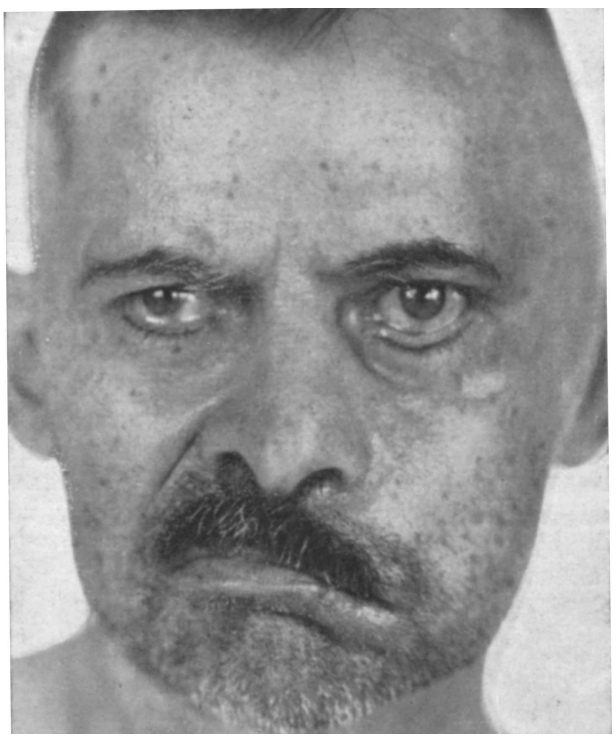

Fig. 5-Caso 8: paralisia facial à esquerda; abaulamento da região temporal ipsolateral. e acuidade visual normais. Midriase à direita. Motilidade ocular extrinseca normal, bilateralmente. Hipoestesia superficial na hemiface esquerda; reflexo corneano abolido dêsse lado. Paralisia facial tipo periférico, ả esquerda (fig. 5); ageusia nos dois terços anteriores da hemilíngua ipsolateral. A esquerda, intensa hipoacusia de tipo misto; prova calórica prejudicada à esquerda, pela obstrução do conduto auditivo externo; normorreflexia canalicular à direita; à prova rotatória, tanto para a direita, como para a esquerda, observa-se nistagmo de curta duração, bem mais intenso no globo ocular direito, acompanhado de sensação vertiginosa, sem náuseas. $\mathrm{Pa}-$ resia velofaringea e hipoestesia, à esquerda; estase salivar no seio piriforme esquerdo. Paralisia da hemilaringe do mesmo lado. Hipogeusia no têrço posterior da hemilingua esquerda. Hipotrofia do trapézio esquerdo, mais nitida em sua porção superior; déficit do esternoclidomastóideo esquerdo. Motilidade da língua conservada, notando-se tremores ao ser lateralizada para a esquerda.

Exames complementares - Craniograma: sinais de extenso processo osteolitico da pirâmide petrosa esquerda, desde a porção medial até o ápice; velamento dos seios esfenoidais, com rarefação difusa do soalho e dorso selares. Carótido-angiografia esquerda: grande massa tumoral na região cérvico-facial (invadindo a base do crânio), ricamente vascularizada; seus aferentes são ramos da carótida externa. Liqüido cefalorraqueano (punção suboccipital): pressão inicial 20; límpido e incolor; 0 célula; proteínas $30 \mathrm{mg} / 100 \mathrm{ml}$; reação de Pandy positiva; reação do benjoim 
01221.22210.00000.0; outras reaçōes normais. Biopsia da massa tumoral do conduto auditivo externo: paraganglioma acromafino, provàvelmente de origem jugular.

CAso 9 - Comprometimento dos $I I, I I I, I V, V, V I$ e VIII nervos cranianos à direita, e dos II, VI e VIII à esquerda. Necropsia: sarcoma fusocelular da fossa média.

P.A., com 48 anos de idade, branco, brasileiro, admitido na Clínica Neurológica em 26-8-1948. Início da moléstia há um ano: dores na hemiface direita; diminuição progressiva da audição, do mesmo lado; protrusão do globo ocular direito; diplopia e diminuiçāo da acuidade visual à direita. Em junho 1948 submetera-se a sinusotomia maxilar bilateral. Exame clinico - Paciente torporoso, em mau estado geral, subfebril. Região temporofrontal direita dolorosa à percussāo. Exame otorrinolaringológico: infiltração edematosa do corneto médio, com secreção do meato, à esquerda.

Exame neurológico - Hiperreflexia profunda, sem outros sinais de comprometimento de estruturas nervosas centrais. Nervos cranianos: Acuidade visual: à direita, percepção luminosa má; à esquerda, 0,2. Edema incipiente da papila direita. Paralisia dos nervos III, IV e VI à direita; paralisia do abducente esquerdo. Anestesia da córnea e hemiface, à direita. Diminuição da acuidade auditiva em ambos os lados; normorreflexia vestibular. Discreto repuxamento do palato mole para a esquerda, à movimentação.

Exames complementares - Craniograma: forame óptico deformado, com limites irregulares à direita; imprecisão dos limites da fenda esfenoidal direita; opacificação difusa e homogênea do fundo orbitário; sela turca ligeiramente alterada em sua morfologia. Liqüido cefalorraqueano (punção suboccipital): pressão inicial 12; límpido e incolor; 12,3 células $/ \mathrm{mm}^{3}$ (linfócitos $74 \%$, monócitos $26 \%$ ); proteinas 40 $\mathrm{mg} / 100 \mathrm{ml}$; reações de Pandy e Nonne-Apelt positivas; reação do benjoim 12222. 22221.00000 .0 ; outras reações normais. Carótido-angiografia direita: parada do contraste ao nivel do sifão carotídeo.

Evolução - Quatro dias após o paciente faleceu. Necropsia (SS 27275/49, Dr. Osvaldo Arruda Behmer): Nariz e bôca sem alterações dignas de registro. Base do crânio deformada por grande formação tumoral, ocupando a região da sela turca e partes mediais das fossas cranianas médias, e inteiramente revestida pela dura mater, cujo aspecto é normal. A palpação e num corte frontal passando pelo pedúnculo hipofisário observa-se erosão das apófises clinóides, do dorso e das paredes laterais da sela turca. Anteriormente, a massa tumoral invade o ápice de ambas as órbitas e os seios maxilares. Os nervos cranianos II a VI, as carótidas internas e os seios cavernosos de ambos os lados estão englobados na neoplasia. Compressão da face basial do encéfalo; quiasma óptico e infundíbulo deslocados para cima; face medial dos lobos temporais e protuberância anular comprimidos pela massa tumoral, especialmente à direita. Aos cortes do cérebro, nada digno de nota. Diagnóstico histopatológico: sarcoma fusocelular.

Comentários sôbre as observações - As observaçôes relatadas exemplificam casos nos quais a sintomatologia neurológica é limitada ao domínio dos nervos cranianos, acometidos de maneira múltipla e, na quase totalidade dos casos, unilateralmente. Em nenhum dos pacientes foram verificados distúrbios neurológicos nos membros. Inexistiam também sintomas de hipertensão intracraniana, embora o exame oftalmoscópico tivesse evidenciado, no caso 1 , discreto ingurgitamento venoso e houvesse discreta hipertensão liquórica nos casos 1 e 8 .

Quanto à idade dos pacientes, os distúrbios se manifestaram entre 5 (caso 6) e 59 anos (caso 4). A coexistência de tumor da rinofaringe foi observada em 4 casos (1, 2, 6 e 7), sugerindo ter sido essa a origem da neoplasia basilar que 
condicionou o desenvolvimento da síndrome paralítica dos nervos encefálicos. No caso 3 tratava-se de tumor misto da parótida, maligno, com invasão do esfenóide e rochedo ipsolaterais. Nos casos 4 e 5 pôde ser afastada a origem nasofaringea, mas não foi determinado, com segurança, se o tumor da base craniana era primitivo ou metastático. No caso 8 a neoplasia tivera origem extracraniana, provàvelmente no glomo jugular. Portanto, apenas no caso 9 pode-se admitir como certo que o tumor (sarcoma fusocelular da fossa média) não procedia de territórios extracranianos.

Adenopatia cervical ou retromandibular era nitida em cinco casos $(1,3,4,5$ e 7). Alterações radiológicas da base do crânio eram evidentes em sete casos (1, $2,3,4,5,7$ e 8 ) e discretas em um (caso 9). A carótido-angiografia, realizada nos casos 3,8 e 9, forneceu valiosas informações para o diagnóstico. Em três casos o exame histopatológico revelou tratar-se de sarcoma (casos 1, 6 e 9), em cinco de carcinoma $(2,3,4,5$ e 7$)$ e, em um, de tumor glómico.

No tocante à sintomatologia, quatro casos (1, 2, 3 e 4) configuram tìpicamente a sindrome de Garcin, uma vez que prảticamente todos os nervos cranianos de um mesmo lado foram invadidos, globalmente, pelo processo neoplásico. As demais observações, ainda que não apresentem completa a sindrome paralítica unilateral dos nervos cranianos, mostram paralisias múltiplas dos nervos, destituidas, embora, de uma sistematização bem definida. O comprometimento inicial dos nervos do andar médio surgiu como o mais freqüente, apenas sobressaindo a invasão preponderante dos últimos nervos no caso 7. A associação dos nervos comprometidos lembrava, no caso 7 , a sindrome de Villaret, acrescida de sinais de lesão do nervo auditivo. No caso 8 (tumor glômico) os nervos V, VII, VIII, IX, X e XI encontravam-se invadidos pelo processo neoplásico.

Sintetizando: em todos os casos, a ocorrência exclusiva ou predominantemente unilateral das paralisias de nervos encefálicos, aliada aos demais atributos clínicos dos tumores basilares intracranianos (mormente a ausência de hipertensão intracraniana e de transtornos neurológicos apendiculares) permitiu o reconhecimento dêsse tipo de neoplasia. Deve ser sublinhado o interêsse particular do exame radiológico simples; na maioria dos casos as alterações osteolíticas contribuíram positivamente para a distinção entre êstes processos tumorais e condições outras, capazes de originar quadro clínico semelhante. Neste sentido exporemos, ao cuidar do diagnóstico diferencial, a interessante observação de um paciente, cuja sintomatologia, também essencialmente constituida por paralisia predominantemente unilateral de nervos cranianos ( $\mathrm{V}$ ao XII), levantou questões de diagnóstico diferencial entre tumor da base e tumor do tronco encefálico. Contra esta hipótese depunha, sobretudo, a inexistência de perturbações neurológicas apreciáveis nos membros, apresentando-se pràticamente pura a sindrome paralítica dos nervos encefálicos, visto que as alterações do equilibrio verificadas podem ser interpretadas como decorrentes de lesão do contingente vestibular do VIII nervo. Por outro lado, a perfeita normalidade do exame radiológico da base do crânio constituia importante elemento a considerar-se, no sentido de ser relegado a um segundo plano o diagnóstico de neoplasia basilar.

\section{CONSIDERACÓES CLINICAS SOBBRE OS TUMORES BASILARES}

Nos tumores extracranianos, os primeiros sinais podem ser devidos a lesão de estruturas localizadas em pontos distantes da origem, como ocorre em alguns tumores rinofaríngeos, em que os sinais neuroparalíticos abrem a cena clínica. Nos neoplasmas primàriamente intracranianos, as manifestações iniciais serão representadas por fenômenos deficitários ou irritativos dos nervos cranianos atingidos. Num e noutro caso as neoplasias terminam por constituir paralisias associadas de nervos cranianos, já descritas há 
muito: síndromes da fenda esfenoidal, do ápice orbitário (Rollet ${ }^{107}$ ), da parede lateral do seio cavernoso (Foix ${ }^{39}$ ), da encruzilhada petrosfenoidal (Ja$\operatorname{cod}^{56}$ ), do ápice do rochedo (Gradenigo ${ }^{46}$ ), do forame despedaçado posterior (Vernet ${ }^{129}$ ), dos forames condiliano e jugular (Collet 28 e Sicard 116), do espaço retroparotídeo (Villaret ${ }^{130}$ ) e do ângulo pontocerebelar. Além destas sindromes cumpre destacar, como mais precoces e caracteristicas dos tumores rinofaríngeos, a triade de Trotter 128 (hipoacusia por obstrução tubária, paralisia velopalatina de origem mecânica, neuralgia no território do ramo mandibular do trigêmeo) e a sindrome de Goldtfredsen ${ }^{44}$ (oftalmoplegia extrínseca parcial, geralmente por paralisia do abducente, neuralgia do trigêmeo e glossoplegia, as primeiras devidas à invasão intracraniana do tumor e esta última, à compressão do hipoglosso por adenopatia metastática). Em vista do crescimento neoplásico, essas síndromes, de parciais que eram no início, se combinam entre si e terminam por constituir uma sindrome unilateral global de nervos cranianos.

Unilateralidade das paralisias - Hartmann ${ }^{49}$, em 1906, já frisara que os tumores da base do crânio se traduzem por extensas "paralisias cranianas de um só lado". Oppikofer 88 salientou que as paralisias dos nervos cranianos eram sempre unilaterais e do mesmo lado do tumor rinofaríngeo.

Garcin ${ }^{41}$ emprestou grande valor à natureza do tumor na produção de sintomas uni ou bilaterais; estabeleceu, mesmo, que os sarcomas ósseos ou meníngeos da base podem lesar todos os nervos cranianos sem ultrapassar a linha mediana. Nos carcinomas, entretanto, a bilateralidade das paralisias já não seria tão rara ${ }^{11}$. Todavia, exceções a essa regra têm sido registradas, bastando lembrar que, já em 1921, Roger e col. ${ }^{104}$ haviam publicado um caso de mixossarcoma da base, que determinara paralisias bilaterais de vários nervos cranianos.

Para Worms e Carillon ${ }^{137}$, a regra da unilateralidade não é absoluta, sendo geralmente observada nos neoplasmas pouco expansivos; em alguns de seus casos houve paralisia bilateral do $\mathrm{V}$ e VI nervos devido à invasão em ponte das fossas médias. Bilateralidade de sinais paralíticos também foi notada por Bonnahon ${ }^{16}$ e em 23 casos de Godtfredsen ${ }^{44}$. Riggs e col. ${ }^{102}$ observaram a invasão de nervos contralaterais, em fases finais da evolução, em 6:11 casos de tumores da rinofaringe. Oya e Segovia ${ }^{91}$ frisam que a transposição da linha mediana se efetua pela apófise basilar ou através do seio esfenoidal.

Ausência de hipertensão intracraniana - Este caráter é também a regra nesses casos, o que pode levar a erros diagnósticos, pela rejeição da hipótese de tumor intracraniano. São excepcionais os casos ( 2 de Needles ${ }^{84}$, 2 de Worms e Carillon ${ }^{137}$, o caso 13 de Rosenbaum e Seaman ${ }^{111}, 8$ casos de Godtfredsen ${ }^{44}$, um de Riggs e col. ${ }^{102}$, e os casos de Roger e Paillas ${ }^{106}$, Léchelle e col.66 e Montanaro e col. ${ }^{82}$ ), em que estavam presentes sinais de hipertensão intracraniana. Segundo Garcin ${ }^{41}$, a origem do fato estaria numa "trepanação espontânea", ou melhor, numa verdadeira craniotomia descompressiva realizada pelo tumor. 
Para Simmons e Ariel 119, papiledema e outros sinais de hipertensão só se verificam no periodo final, geralmente após invasão da fossa posterior. O edema de papila constitui mais um sinal local ${ }^{89}$ ou a expressão do edema reacional de vizinhança 114 do que um índice de elevação da pressão intracraniana, o que é atestado pelo fato de freqüentemente ser ipsolateral ao tumor.

Inexistência de sinais de lesão das estruturas nervosas centrais - Os tumores da base respeitam, em geral, a dura madre, como já fôra assinalado por Oppikofer ${ }^{88}$. Destarte, não costumam ser lesados os centros nervosos encefálicos. Mas, mesmo que rompam as meninges, podem, em razão da eventual lentidão do crescimento, penetrar no parênquima nervoso sem produzir sintomatologia, ou pelo menos não proporcionada a seu volume. O tecido nervoso central se adapta a tempo à invasão neoplásica.

Convém ter presente, porém, a possibilidade de lesões do tronco encefálico, do cerebelo ou dos hemisférios cerebrais. Assim, em 6 dos 150 casos de Simmons e Ariel 119, havia lesão cerebral que, em 2 pacientes, se acompanhava de encefalomalacia frontal; em 3 dos 24 casos de Rosenbaum e Seaman ${ }^{111}$ havia hemiparesia; $\mathrm{em}$ um caso de Needles ${ }^{84}$ havia sinais piramidais; no de Ballenger ${ }^{12}$, o tumor invadiu os lobos temporal e frontal e a ponte; no de Linneu Silva e col. ${ }^{118}$ foram verificadas lesões de circunvoluções cerebrais. Num dos casos de Garcin ${ }^{41}$, a neoplasia invadiu a base da protuberância sem produzir, porém, sinais sensitivos ou motores, o que foi atribuído à dissociação das fibras nervosas pela massa neoplásica. Sinais piramidais, cerebelares ou sensitivos têm sido observados, ao lado das paralisias de nervos cranianos, em casos de tumores glômicos $2,13,98,134$.

\section{Neoplasias de origem extracraniana}

Entre os tumores (sensu latu) de origem extracraniana avultam as neoplasias do cavum, mas devemos não esquecer outras entidades mórbidas, como os tumores glômicos, o linfogranuloma maligno, os tumores da parótida, os neoplasmas metastáticos.

1. Tumores da rinofaringe - Estas neoplasias têm constituído objeto de inúmeros trabalhos, salientando-se, pelo vulto da casuística, o de Godtfredsen ${ }^{44}$ (454 casos) e, entre os mais recentes, os de Mekie e Lawley ${ }^{77}$ e Molony ${ }^{80}$.

As cifras relativas à incidência dos blastomas rinofaríngeos entre os diversos tumores malignos variam entre 0,1 e 2,0\% (Ducuing e Ducuing ${ }^{34}$, Godtfredsen ${ }^{44}$, Martin ${ }^{73}$, Nielsen ${ }^{87}$, Simmons e Ariel ${ }^{119}$ ). Essas neoplasias se instalam geralmente dos 40 aos 60 anos $65,84,85 a, 88,91,113,138$; a média etária nos casos de Godtfredsen ${ }^{44}$ com sinais neuroftalmológiocs foi de 49,5 anos. Predominam no sexo masculino $65,120,138$, em percentagens que variam de 2:1 (Godtfredsen ${ }^{44}$, Kleinfeld ${ }^{59}$, Needles ${ }^{84}$, Scevola ${ }^{114}$ ), 3:1 (Digby e $\operatorname{col}^{33}$ e Mekie e Lawley ${ }^{77}$ ) até $7: 1$ (Molony ${ }^{80}$ ). Tem sido assinalada maior 
incidência dessas neoplasias entre os povos orientais ${ }^{17}$, especialmente chineses $33,77,80$, onde a freqüência atinge $27,2 \%$ dos tumores malignos em geral 33

As neoplasias de origem epitelial são mais freqüentes que os sarcomas $\left(55,3 \pm 2,3 \%\right.$ para $44,7 \pm 2,3 \%$, segundo Godtfredsen $\left.{ }^{44}\right)$. As subdivisões dentro dêstes dois grupos ainda constituem motivo de controvérsia 44,114 e por isso não as abordaremos.

Woltman 136 já assinalara a freqüência com que a fosseta de Rosenmüller constitui a sede inicial dessas neoplasias. Scevola ${ }^{114}$ observou predomínio percentual dos tumores originados na parede lateral da faringe (blastomas tubários e peritubários), seguindo-se-lhes os situados nas paredes superior, anterior e posterior.

A invasão do crânio varia conforme o local de implantação do tumor, se na parede lateral ou no teto da rinofaringe. Note-se que a fosseta de Rosenmüller se situa imediatamente abaixo da margem medial do forame despedaçado anterior (figs. 6 e 7); a neoplasia precisa crescer apenas $1 \mathrm{~cm}$ para atingir o espaço intracraniano, sem erosar o osso. $O$ tumor, então,

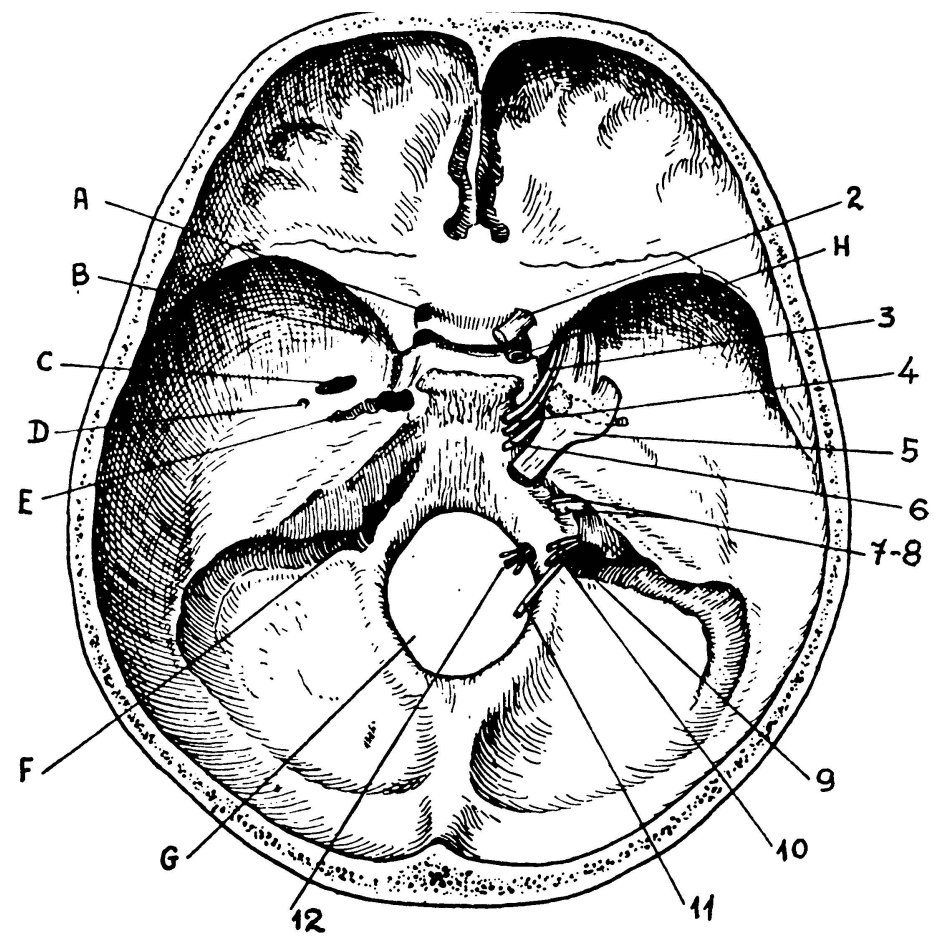

Fig. 6 - Base do crânio. Forames: $A$, óptico; $B$, redondo; $C$, oval, $D$, espinhoso; $E$, despedaçado anterior; $F$, jugular; $G$, magno. Em números os respectivos nervos cranianos. Reprodução autorizada da figura 2 do trabalho de Martin $e$ Blady ${ }^{74}$. 
geralmente se difunde para a ponta do rochedo, produzindo uma síndrome de Gradenigo; sua extensão ulterior a regiões mais mediais determina o estabelecimento de uma síndrome de Jacod. Nos demais casos, a invasão se processa ao longo dos troncos nervosos que atravessam os orifícios da base naturalmente pérvios ${ }^{106}$ ou com o concurso de vias sangüíneas e linfáticas existentes entre a abóbada da nasofaringe e a cavidade craniana, ou ainda através das suturas basilares. Os nervos bulbares podem ser lesados no exterior do crânio (síndromes de Vernet e de Collet e Sicard) e na região retroparotídea pode associar-se a lesão do simpático (síndrome de Villaret); tal acometimento pode ser produzido pelo próprio tumor ou pelos gânglios linfáticos enfartados, fato que ocorria em 86,5\% dos 150 casos de Simmons e Ariel ${ }^{119}$.

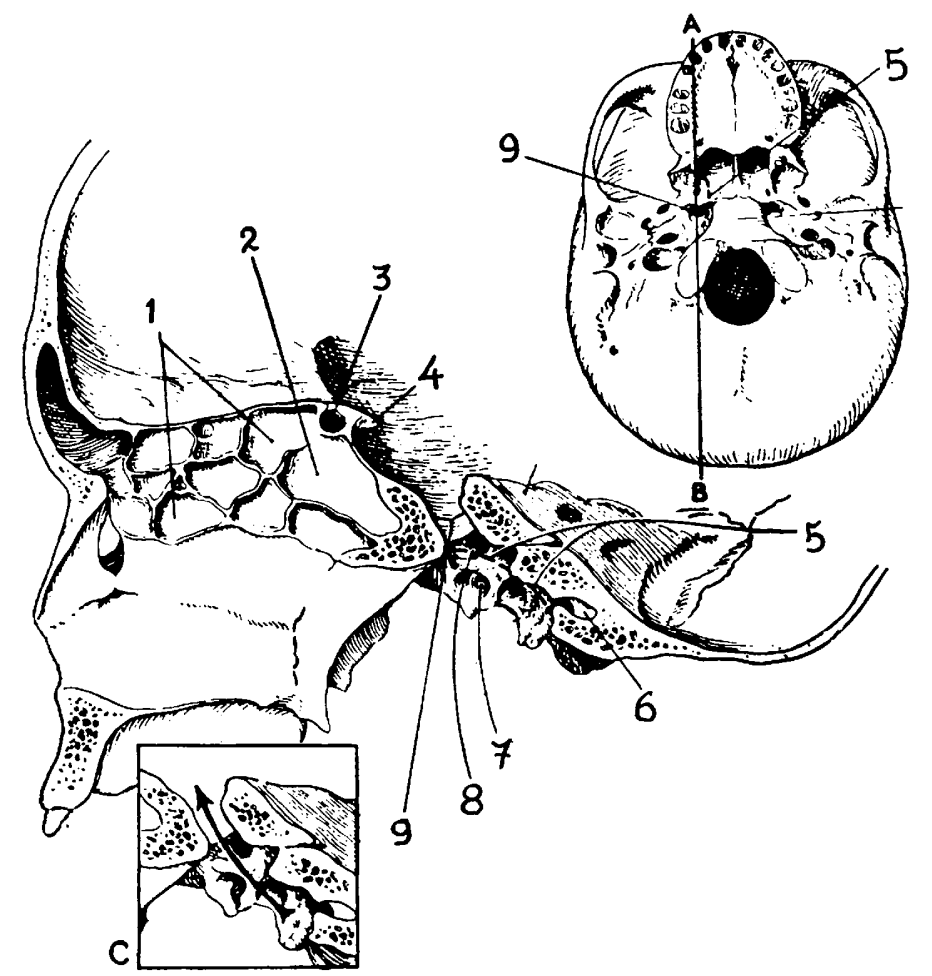

Fig. 7 - Corte sagital do crânio e face externa da base. 1, células etmoidais; 2, seio esfenoidal; 3, forame óptico; 4, processo clinóideo anterior; 5, recesso faríngeo (fossa de Rosenmüller); 6 , canal condiliano; 7 , óstio tubário; 8, canal carotídeo; 9 , forame despedaçado anterior. Reprodução autorizada da figura 3 do trabalho de Martin e Blady".

Invadido o crânio, o tumor permanece aderente aos ossos da base 14, 114 . Segundo Simmons e Ariel ${ }^{119}$, a invasão da dura mater é muito rara, não 
tendo sido observada em nenhum de seus 150 casos. Riggs e col.102 verificaram, em vários casos, a inexistência de correlação entre lesão óssea e comprometimento dos nervos cranianos; em 7:11 casos havia propagação do tumor à cavidade craniana e, em nenhum, êle se confinara ao espaço subdural; em alguns casos a invasão da dura madre pôde ser demonstrada microscòpicamente; em 3 casos comprovaram disseminação subaracnóidea da neoplasia, fato que possibilitaria a lesão de nervos cranianos antes de sua emergência da paquimeninge.

Ao contrário do que se poderia supor, os tumores nasofaringeos nem sempre produzem sintomas iniciais no dominio topográfico de origem. Mesmo o exame cuidadoso da rinofaringe pode não revelar alterações definidas, principalmente quando as neoplasias se iniciam na região peritubária ${ }^{80,137}$, sede mais habitual de sua implantação.

Revendo a literatura, Godtfredsen ${ }^{44}$ apurou que, em $26,1 \%$ dos casos, os enfartamentos ganglionares constituíam a manifestação inicial; computando-se os dados de Scevola 114, Molony 80 e Simmons e Ariel 119 (325 casos) obtém-se a média de $35,5 \%$.

A freqüência dos sintomas ctológicos (sensação de plenitude e de abafamento no ouvido, tinido e hipoacusia) entre as manifestações iniciais varia consideràvelmente segundo os autores; as cifras médias giram em tôrno de $15 \%$.

O crescimento do tumor para baixo ou para a frente, com invasão das fossas nasais, é raro, só ocorrendo nas fases terminais. Sua freqüência como manifestação inicial varia entre 3\% (Simmons e Ariel ${ }^{119}$ ) e 33\% (Martin e Blady ${ }^{74}$ ). Deve ser feita biopsia de qualquer zona suspeita, embora a negatividade dêsse exame não exclua definitivamente a hipótese de tumor 80,111 .

Os sintomas neuroftalmológicos já haviam sido salientados por Soucy 120 em 1911. São geralmente representados por trigeminalgias; para Brock ${ }^{18}$, representam 50\% dos sintomas neurológicos precoces e podem permanecer isolados durante longo período da evolução ${ }^{137}$. Sintomas neuroftalmológicos isolados constituíram as manifestações iniciais em $16 \%$ dos casos de Godtfredsen ${ }^{44}$, que também comprovou a maior freqüência das neuralgias. À trigeminalgia segue-se a paralisia do abducente ${ }^{80}$. Salinger e Pearlman ${ }^{113}$ salientam que a presença de sinais de lesão de nervos cranianos, além dos de comprometimento dos ramos maxilar e mandibular do trigêmeo, indicam invasão do crânio pelos forames da fossa média, fissura orbitária e/ou forame jugular e constituem indício de um estádio irreversivel da moléstia.

Manifestaçōes oculares raramente constituem sinais precoces; Needles ${ }^{84}$ observou êste fato apenas em 3:79 casos. Também é excepcional que os sintomas otológicos e nasais surjam associadamente, como aconteceu em 3 casos de Scevola ${ }^{114}$. Os sintomas gerais são representados por anemia, caquexia, astenia, metástases em órgãos remotos ou invasão de seios paranasais e da órbita. 
Durante 12 a 15 meses, em média, a lesão da rinofaringe costuma permanecer assintomática ${ }^{44}$. Por outro lado, a aparente benignidade de alguns dos sintomas iniciais constitui, freqüentemente, causa de atraso na procura do médico por parte do paciente: apenas em $26 \%$ dos 150 casos de Simmons e Ariel 119 o especialista foi procurado menos de 1 mês após o início dos sintomas; a duração média dêsse período varia entre 3,2 meses (Simmons e Ariel 119) e 9,5 meses (Mc Whirter ${ }^{76}$ ). Entretanto, Simmons e Ariel ${ }^{119}$ imputam aos médicos a maior parte da culpa pelo atraso no diagnóstico, pois verificaram que, em $61,3 \%$ dos casos, o primeiro médico procurado errou o diagnóstico. Nas séries de Furstenberg ${ }^{40}$ e Mekie e Lawley ${ }^{77}$, o diagnóstico correto só foi estabelecido, em média, 15 e 12 meses, respectivamente, após o aparecimento dos primeiros sintomas. Na série de Woltman ${ }^{136}$, o êrro diagnóstico perdurou mais de um ano em 14,6\% dos casos; esta cifra, embora de 1949, não deve ser atribuída a deficiência de recursos técnicos, pois, em 1957, Molony ${ }^{80}$ referia que o êrro diagnóstico durara cêrca de 3 meses. Nos casos em que as manifestações iniciais eram do domínio neurológico, os erros mais freqüentes ${ }^{136}$ foram: tumor do ângulo pontocerebelar, neurolues, lesão do sistema nervoso central.

$\mathrm{Na}$ fase de estado, a proporção de sintomas oftalmoneurológicos se elevou a $38 \%$ na série de Godtfredsen ${ }^{44}$.

Quanto aos nervos cranianos mais freqüentemente acometidos na fase de estado, as cifras são bastante variáveis. Godtfredsen ${ }^{44}$ refere que $68 \%$ de seus 172 casos com sintomas neuroftalmológicos apresentavam sinais trigeminais; paralisias de nervos oculares foram observadas em $46,3 \%$ dos casos. Os autores, em geral $18,53,77$, referem maior índice de comprometimento dos nervos V e VI, o que explica a freqüência com que se constitui a síndrome de Gradenigo. Note-se, a propósito, a raridade do comprometimento do contingente motor do trigêmeo ${ }^{102}$.

Os quatro últimos nervos são habitualmente lesados no espaço extracraniano, por expansão tumoral ou por gânglios metastáticos. A paralisia do véu pode ser devida à pressão direta do tumor no espaço perifaríngeo ou ao comprometimento do músculo elevador do palato ${ }^{136}$.

Babonneix e Sigwald 11 acentuam que, embora os nervos cranianos sejam simultâneamente comprometidos devido ao crescimento rápido e contínuo da neoplasia, a síndrome resultante pode ser saltuária, pois alguns nervos resistem mais. Enquanto o oculomotor e o abducente se mostram mais vulneráveis, o facial e o auditivo costumam ser mais refratários 44, 45, 119 . O VII não foi lesado em nenhum dos 16 casos de Woltman ${ }^{136}$, dos 22 de Oya e Segovia ${ }^{91}$ e dos 3 de Romay e Blumtritt ${ }^{108}$. A preservação do nervo facial foi atribuída ao fato do tumor geralmente se interromper na crista do rochedo ${ }^{137}$, onde também encontra a barreira representada pela tenda do cerebelo ${ }^{15}$; Cushing (cit. por Gotor ${ }^{45}$ ) verificou que o VII e o VIII são os nervos menos vulneráveis à distensão e à compressão.

Raramente ocorrem sinais de comprometimento do nervo olfativo; a anosmia, na maioria das vêzes, resulta da invasão neoplásica da mucosa nasal. 
Lesões de raizes cervicais foram observadas em alguns casos $37,60,71$. A síndrome de Claude Bernard-Horner é relativamente freqüente ${ }^{111}$ e se deve ao comprometimento das vias simpáticas, seja quando penetram no crânio juntamente com a carótida, seja como resultado de compressão por gânglios metastáticos cervicais, ou ainda pela invasão do espaço retroparotídeo.

2. Tumores glômicos - Os tumores glômicos (paragangliomas acromafinos, quemodectomas ou glomangiomas) do segmento cefálico constituem neoplasias de evolução muito lenta, originadas de estruturas neuro-mio-arteriais (Masson, cit. por Maffei ${ }^{72}$ ) situadas na adventícia do bulbo da jugular ou da bifurcação da carótida, ou ainda no trajeto intrapetroso do nervo timpânico. Podem desenvolver-se em direção da mastóide e se exteriorizar na região retro-auricular, ou erosar o rochedo em direção da fossa posterior, ou ainda seguir o trajeto tubário, aflorando na rinofaringe.

Quando localizados no forame jugular podem determinar a síndrome de Vernet ou mesmo a de Sicard e Collet. Tem sido descrito o comprometimento do facial e dos nervos motores oculares. Em nosso caso 8 havia, além da síndrome condilojugular, nítidos sinais de lesão dos V e VII nervos. Segundo Garcin e col.42, a sindrome otológica se caracteriza por otalgia, ruídos subjetivos rítmicos, surdez progressiva de tipo condução, hipoexcitabilidade labirintica e alterações timpânicas. Essa síndrome ocorria em nosso caso, porém, a surdez era de tipo misto.

Para o diagnóstico ressalta a importância da otoscopia, que revela massa poliposa no conduto auditivo, e do exame radiológico, que, segundo o estádio evolutivo do tumor, demonstra, desde opacificação da mastóide, até erosão e destruição do rochedo e alargamento do forame jugular.

De 31 casos de tumores glômicos estudados por Bartels 13, 11 apresentavam comprometimento de nervos cranianos. Henson e col.51 coletaram 31 casos (inclusive 5 pessoais) de tumores do glomus jugulare apresentando comprometimento de nervos cranianos, particularmente do VII e dos bulbares. Weiss ${ }^{132}$ observou 4 casos de paralisia múltipla unilateral de nervos cranianos determinada por tumores angiomatosos do glomus caroticus. Cumpre citar, ainda, os casos de tumores glômicos registrados por Riemenschneider e col. ${ }^{100}$ e Roger ${ }^{103}$.

Em nosso meio há vários trabalhos versando o problema dos tumores glômicos; contudo, apenas em um dos 12 casos estudados por Rezende e col. ${ }^{99}$ e Maffei ${ }^{72}$, constituiu-se uma síndrome paralítica de vários nervos cranianos (do VI ao XII). Nosso caso 8 constitui, portanto, o segundo da literatura nacional a apresentar sintomatologia neurológica exuberante, no domínio dos nervos encefálicos.

3. Linfogranuloma maligno, linfomas e leucemia - A moléstia de Hodgkin pode, através do comprometimento dos gânglios linfáticos subcranianos, produzir compressão dos nervos que emergem pelos orifícios das fossas mé- 
dia e posterior, além de lesar o facial na altura do forame estilomastóideo (caso de Lafon e col.62); eventualmente, invade o crânio (caso de Staffieri e col. $\left.{ }^{122}\right)$. Relatamos, a seguir, um caso de paralisia múltipla unilateral de nervos cranianos determinada por linfogranuloma.

J.B.O., com 18 anos de idade, prêto, brasileiro, examinado na Clínica Neurológica em 15-10-1948 (reg. HC 115398). Há 8 anos, enfartamento ganglionar na região ingüinal esquerda; há um ano, adenopatia cervical bilateral, mais nítida à esquerda. Há 5 meses, dores na hemiface esquerda e diplopia. Ulteriormente, hipoacusia e ptose palpebral à esquerda, e desvio da bôca para a direita. O paciente estêve internado no Departamento de Medicina do Hospital das Clinicas (3* Clínica Médica), onde foi estabelecido o diagnóstico de moléstia de Hodgkin. Exame físico - Enfartamento ganglionar na região súpero-lateral esquerda do pescoço.

Exame neurológico - Nenhuma alteração motora, sensitiva ou da coordenação nos membros. Nervos cranianos: Oftalmoplegia à esquerda, com ligeiro estrabismo divergente; reflexos pupilares diminuídos à esquerda. Acuidade visual normal no ôlho direito e de 0,7 no esquerdo; ligeira palidez da papila esquerda. Hipoestesia superficial da hemiface esquerda; reflexo corneano diminuido dêsse lado. Paralisia facial, de tipo periférico, à esquerda. Hipoacusia dêste mesmo lado.

Evolução - Em virtude da intensidade da trigeminalgia, o paciente foi submetido a neurotomia retrogasseriana. A intervenção, o cirurgião verificou estar a dura mater infiltrada por tecido friável, lardáceo, que mascarava a regiāo e invadia a fossa média e o gânglio de Gasser. O exame histopatológico revelou tratar-se de tecido colágeno denso, com infiltrado inflamatório crônico.

Nas leucemias e linfomas o tumor pode disseminar-se pelo espaço subaracnóideo, vindo a comprometer vários nervos cranianos; o crânio e as estruturas nervosas centrais podem ser poupados (Riggs e col. ${ }^{102}$ e Sparling e $\left.\operatorname{col}^{121}\right)$.

4. Tumores da parótida - Voto-Bernales e col. ${ }^{131}$ e Arana fñiguez e col. ${ }^{6}$ relataram casos de paralisias múltiplas de nervos cranianos produzidas, respectivamente, por tumor misto e esquirro da parótida. Em nosso caso 3 constituiu-se uma síndrome paralítica global (apenas o nervo olfativo foi poupado), unilateral, subordinada à invasão do crânio por um adenocarcinoma da parótida.

5. Tumores metastáticos - Síndromes paralíticas de vários nervos encefálicos foram registradas por Babonneix e Sigwald ${ }^{11}$, Guillain e col.48, Asenjo e col. ${ }^{7}$ e Mounier-Kuhn ${ }^{83}$. Kojevnikoff ${ }^{60}$ referiu um caso de paralisia de todos os nervos cranianos, exceto o facial, que se interpôs a duas metástases de carcinoma cervical, uma alojada no ângulo pontocerebelar e outra na fossa média; no período final o VII também veio a ser lesado.

6. Branquiomas - Lorente e Garcia ${ }^{69}$ relataram um caso de neoplasia subdural da base com extensão para a rinofaringe e comunicação com um tumor cervical; havia lesão do lobo temporal e dos nervos III a XII. Tratava-se de epitelioma originado de restos branquiais do pescoço, e não de craniofaringioma. 
Neoplasias primitivas do crânio ou de estruturas intracranianas

1. Meningiomas - André-Thomas ${ }^{4}$ registrou um caso de meningioma da fossa posterior, com paralisia dos seis últimos nervos cranianos, que se aproximava dos de Garcin pela aparição muito tardia do papiledema e dos sinais de lesão dos centros nervosos. Montanaro e col. ${ }^{82}$ relataram um caso de meningioma em criança, responsável por paralisia global unilateral dos nervos cranianos, sem outros sinais neurológicos a não ser discreta hiporreflexia contralateral. Cruz e Tenuto ${ }^{32}$ descreveram um caso de paralisia dos nervos III a VIII, à esquerda; havia, além disso, edema de papila ipsolateral, provàvelmente relacionado diretamente com a neoplasia e não com hipertensão intracraniana; inexistiam sinais de lesão do sistema nervoso central.

2. Malformações vasculares - Os angiomas do ouvido médio, assim como vimos em relação aos tumores glômicos, podem destruir o rochedo e comprometer vários nervos cranianos. No caso 1 de Carrea e Insausti ${ }^{22}$ houve uma síndrome de Rigaud e Sendrail ${ }^{101}$, caracterizada por paralisia do V, VII e VIII associada à síndrome de Collet e Sicard. Carrea e Insausti coletaram mais 11 casos da literatura, merecendo menção os três de Goekoop, os dois de Hampton e Sampson, e os de Busacca e de Frazer; em alguns dêles havia sinais de hipertensão intracraniana.

3. Craniofaringiomas e cistos epidermóides - Furstenberg ${ }^{40}$ relatou 2 casos de paralisias múltiplas de nervos oculares atribuídas a neoplasia derivada de restos do ducto faringo-hipofisário. Em recente trabalho ${ }^{21}$, um de nós (H.M.C.) teve oportunidade de registrar, entre 26 casos de craniofaringioma, dois com sintomatologia paralítica de nervos cranianos: no caso 14 (tumor intracrânio-selar com destruição do seio esfenoidal) havia comprometimento unilateral dos nervos V, VII e VIII; caso 22, o tumor, com idênticos atributos topográficos e histopatológicos (carcinoma planocelular com caracteres de malignidade), determinou, a par de uma sindrome cerebelopiramidal, paralisia dos nervos III, IX e X à direita, do hipoglosso esquerdo e, bilateralmente, do V e VI; em ambos os casos não havia papiledema. Éstes casos, portanto, contrariam a opinião de Jackson ${ }^{55}$, de que os craniofaringiomas não comprometem nervos cranianos situados caudalmente ao abducente.

Nos cistos epidermóides do território vertebrobasilar pode configurar-se a síndrome do ângulo pontocerebelar. Lepoire e Pertuiset ${ }^{67}$ observaram, entre 100 casos dessas neoplasias congênitas, um da variedade topográfica basilar, em que se constituiu uma síndrome de Garcin. Um de nós (H.M.C.) ${ }^{20}$ consignou, entre 12 casos de cistos epidermóides, 3 com paralisias de nervos cranianos: nos casos 6 e 7 constituíra-se uma sindrome do ângulo pontocerebelar e, no caso 8 , além de sinais cerebelopiramidais, notava-se paralisia unilateral dos nervos V, VIII, IX, X e XII; em todos êles a síndrome de hipertensão intracraniana era manifesta. 
Mencionaremos aqui também um caso relatado por Rozsival e Schrottenbaum ${ }^{112}$, de adenocarcinoma supra-selar originado em coristoma endodérmico do infundíbulo, que determinou paralisia unilateral global dos nervos cranianos; os autores afirmam não terem encontrado caso semelhante na literatura.

4. Cordomas - Garcin ${ }^{41}$ salientava que os cordomas, sendo medianos, geralmente determinam paralisia bilateral de nervos cranianos e se acompanham de hipertensão intracraniana e sinais centrais; entretanto, já excetuava desta regra o caso de Linck ${ }^{68}$. Ulteriormente, outros casos de paralisias múltiplas de nervos cranianos determinadas por cordomas foram registrados por Camauer e Sacon ${ }^{19}$, Godtfredsen ${ }^{44}$ (unilaterais), Tinel e col. ${ }^{123}$ e Asenjo e col. 7 (bilaterais).

5. Sarcomas - Afora os sarcomas nasofaringeos que invadem a cavidade craniana, há casos de sarcomas primitivos de estruturas intracranianas, causadores de paralisias globais de nervos encefálicos (Guillain e col. ${ }^{4}$, Winter e col. ${ }^{135}$, André ${ }^{3}$, Roger e col. ${ }^{104}$ ).

6. Plasmocitomas - Clarke ${ }^{27}$ descreveu um caso de mieloma da base do crânio, com paralisia de nervos cranianos, e reuniu mais 24 casos semelhantes da literatura, aos quais podemos ainda acrescentar o de Rosenbaum e Seaman ${ }^{111}$.

7. Tumores névicos - Roger e col.105 relataram caso de tumor névico do conduto auditivo, que invadiu o crânio, condicionando uma síndrome paralítica do trigêmeo e dos seis últimos nervos cranianos esquerdos.

8. Neurofibromatose - Pack $^{93}$ referiu um caso de neurofibromatose unilateral dos nervos II, III, IV, VI e VII, com exoftalmo e lesão de nervos cervicais profundos.

Neurocisticercose - Além das neoplasias pròpriamente ditas, também a cisticercose pode determinar comprometimento múltiplo de nervos cranianos; a sede da lesão tanto pode ser periférica como nuclear, pois o parasito atua ou como tumor sensu latu ou através de reações das meninges ou dos vasos. Trelles ${ }^{120}$ referiu um caso de paralisia unilateral dos cinco últimos nervos cranianos, determinada por cisticercose racemosa. Asenjo e Roca 8 estudaram 36 casos de neurocisticercose com lesão de nervos cranianos, sendo que, em 4 pacientes, havia paralisia de seis ou mais nervos; segundo êstes autores, as paralisias múltiplas depõem em faror da forma racemosa. Em nosso Serviço tivemos oportunidade de observar um caso de síndrome do ângulo pontocerebelar.

J.R.S., com 36 anos de idade, internado na Clínica Neurológica em 30-5-1960 (reg. HC 488210). Há 6 anos, neuralgia facial esquerda, contínua, com periodos de exacerbação. Nessa ocasião, o exame neurológico revelava a existência de sinais de lesão dos nervos V e VIII à esquerda e edema das papilas. Três anos após, retornou ao Serviço, com a mesma sintomatologia, acrescida de hemiparesia esquerda. Perante o resultado do exame do 7iqüido cefalorraqueano (normotenso, 12 células/ 
$\mathrm{mm}^{3}$, tipo linfomononuclear, proteinas $30 \mathrm{mg} / 100 \mathrm{ml}$, glicose $39 \mathrm{mg} / 100 \mathrm{ml}$, discreta positividade das reações para globulinas, negatividade das reações de fixação do complemento para sífilis e cisticercose) e da radiografia do crânio, em posição de Stenvers (imagem sugestiva de amputaçăo da ponta da pirâmide petrosa esquerda), foi feito o diagnóstico de tumor do ângulo pontocerebelar. Exames subseqüentes do líquor (inclusive eletroforese das proteínas), porém, vieram demonstrar a etiologia cisticercótica, confirmada ulteriormente à cirurgia e à necropsia.

\section{EXAME RADIOLĆGICO}

A importância diagnóstica do exame radiológico simples, já realçada por Garcin ${ }^{41}$, tem sido constantemente salientada por vários autores 114,137. Orbán 89 frisa que os sinais radiológicos são seis vêzes mais freqüentes que as manifestações neurológicas nos tumores da rinofaringe; por outro lado, segundo Godtfredsen ${ }^{44}$, prevalecem nos carcinomas. Eles ocorriam em 8 de nossos 9 casos.

Garcin ${ }^{41}$ recomendava radiografias de frente e perfil, e nas posições de Stenvers, Hirtz e Rose (mento-vértex). A chapa no plano sagital será particularmente útil no estudo da sela turca e do seio esfenoidal. A de frente permite apreciar especialmente as cavidades orbitárias, nas quais se projetam as pcntas dos rochedos. Pela posição de Stenvers estudam-se os vários elementos da pirâmide. A posição de Hirtz é das mais importantes, pois permite reconhecer a estrutura e a simetria dos pormenores ósseos da base, particularmente da região da encruzilhada petrosfenoidal, sôbre a qual a ampola deve ser focalizada ${ }^{137}$. Para o forame jugular indicam-se as posiçōes de Altschule e II de Chaussé (Insausti e col. ${ }^{53}$ ). Zuppinger ${ }^{138}$ recomendava as posições nucofrontal e ântero-posterior transorbitária e, ainda, a vértex-mento-nariz (projeção da parede lateral da faringe no espaço claro do seio maxilar), nos casos de neoplasia nasofaríngea.

Geralmente, os aspectos observados radiològicamente são representados inicialmente por apagamento das minúcias estruturais da fossa média e depois por hipertransparência aos raios $\mathrm{X}$, surgindo, finalmente, imagens lacunares que, de regra, respeitam dorsalmente a crista superior da pirâmide ${ }^{137}$. As estruturas mais freqüentemente atingidas são o seio esfenoidal e, através dêle, $a^{*}$ sela turca e a lâmina quadrilátera ${ }^{i 5}$. São também encontradiças $\left(56 \%\right.$ dos casos de Godtfredsen ${ }^{44}$ ) as alterações do forame despedaçado anterior.

Em outras eventualidades, em lugar da imagem lacunar e da hipertransparência, observam-se sombras de limites nítidos, devido à projeção do tumor nasofaringeo, que associa sua opacidade à do esqueleto suprajacente, originando um falso aspecto de conđensação óssea ${ }^{137}$.

Entretanto, não se deve considerar o exame radiológico simples como decisivo para o diagnóstico ${ }^{74,111}$. A normalidade das chapas é compatível com a existência de neoplasia basilar, como muito bem demonstra o caso de Monier-Vinard e Brunel $^{81}$, no qual as radiografias, em período relativamente precoce, deixaram de revelar as destruições ósseas que foram patenteadas à necropsia, realizada 4 meses após. De 54 casos de tumor naso- 
faringeo com lesões de nervos cranianos estudados por Mekie e Lawley ${ }^{77}$, apenas $30(55 \%)$ apresentavam sinais de erosão óssea. Tanto basta para tornar imperiosa a repetição dos exames radiológicos ante a suspeita clínica, bem fundamentada, de tumor basilar.

As planigrafias têm grande valor no estudo da rinofaringe. Sichel e col.117 frisam que as tomografias revelam a extensão do tumor e suas relações com as regiões vizinhas e, ademais, permitem distinguir os tumores malignos, dos benignos. Scevola 114 recomendava, no plano sagital, cortes com intervalo de $5 \mathrm{~mm}$, a partir da linha mediana; frontalmente, devem alcançar a profundidade de 9 a $10 \mathrm{~cm}$ em relação ao plano nasofrontal.

O método de Zuppinger 138 para o estudo radiológico contrastado em casos de neoplasias da nasofaringe consiste na introdução de um meio radiopaco no cavum, fazendo-se a radiografia de perfil, em decúbito dorsal e com extensão da cabeça. Normalmente, as paredes posteriores da oro e da rinofaringe são planas; os tumores dessa região determinam o aparecimento de irregularidades nesses contornos.

A pneumocisternografia permitirá estudo minucioso do espaço subaracnóideo basilar, particularmente nos casos em que a neoplasia invade as estruturas medianas, como por exemplo nos cordomas e craniofaringiomas. A pneumoventriculografia também poderá prestar valioso auxílio, revelando defcrmações no sistema ventricular, particularmente no prolongamento temporal dos ventrículos laterais. Ramón Pardal 95 utilizou pela primeira vez (1933) a iodoventriculografia; em seu caso, êsse exame - realizado pessoalmente por Balado - revelou elevação do pólo esfenoidal do ventriculo lateral esquerdo, provocada por um carcinoma extradural da base.

Outro tipo de radiografia contrastada que pode trazer úteis esclarecimentos, especialmente no diagnóstico diferencial, é a angiografia cerebral. Segundo Tolosa ${ }^{125}$, só a arteriografia permite distinção entre aneurismas infraclinóideos e tumores para-selares comprimindo os nervos III a VI e, às vêzes, também o II. Pode observar-se uma série de sinais: modificação na forma do sifão carotídeo (abertura nos tumores da base e do seio cavernoso, achatamento nos meningiomas do têrço medial da pequena asa do esfenóide, forma em ziguezague nos tumores do seio esfenoidal 61, 125), deslocamento da porção basal da artéria cerebral anterior para a linha mediana ${ }^{133}$, deformação do trecho inicial da cerebral média e/ou distensão e abaixamento da corióidea anterior (nos tumores da base, particularmente meningiomas da pequena asa do esfenóide) ${ }^{133}$. Nos tumores da fossa posterior podem ocorrer elevação da cerebral posterior e assimetria no grupo arterial dependente da basilar ${ }^{125}$.

\section{EXAME DO LAQUUIDO CEFALORRAQUEANO}

As informaçōes fornecidas pelo exame do líqüido cefalorraqueano são de ordem negativa no tocante a hipertensão, o que virá afastar a generalidade dos processos neoplásicos do encéfalo. Eventualmente (como em nossos 
casos 2, 5 e 9), nota-se linfocitose variável; o líquor pode, pois, traduzir a irritação meníngea provocada pelo tumor. Em alguns casos observa-se hiperproteinorraquia, associada ou não a pleocitose; como seria de esperar, a existência de dissociação proteinocitológica é mais encontradiça que o incremento isolado dos leucócitos. Needles ${ }^{84}$ observou, em alguns casos, predomínio da fração globulínica, caracterizando a desintegração parenquimatosa (como ocorreu em nossos casos 3,8 e 9, em que a reação do benjoim coloidal mostrou nítida floculação na zona esquerda).

\section{DIAGNOSTICO DIFERENCIAL}

Entre as afecções cuja sintomatologia pode prestar-se a confusão com a dos tumores da base, sobressaem os traumatismos crânio-encefálicos, as polioencefalites, os tumores do tronco encefálico, as meningites basilares e os aneurismas de artérias cerebrais.

Traumatismos crânio-encefálicos — A importância dêstes agentes na produção de paralisias associadas de nervos cranianos é de tal ordem que basta lembrar ter sido durante a primeira grande guerra que as síndromes do andar posterior foram descritas $28,116,129,130$. Em nosso meio, Mello Filho 78 relatou um caso de traumatismo por bala, com lesão do facial no orifício estilomastóideo e dos nervos bulbares junto aos forames jugular e condiliano.

As fraturas do crânio, especialmente do rochedo, também podem determinar paralisias conjuntas de nervos cranianos (Cornil e col. ${ }^{29}$; Aloin, Vernet e Roger, Zwirn e Ourgaud, citados por Garcin ${ }^{41}$ ). Pagniez e col.94 publicaram um caso de paralisia unilateral dos nervos III a XII e do simpático, determinada provàvelmente por hematoma traumático da base craniana.

Os traumas ainda podem atuar indiretamente, como foi observado nos casos de Pachantoni ${ }^{92}$ e Pastine ${ }^{96}$, onde a lesão nervosa foi ocasionada pelo "blast" da explosão ou pelo vento de um obus. Admite-se que, nesses casos, se prcduzam micro-hemorragias na substância nervosa, responsáveis por lesões nucleares dos nervos cranianos.

Polioencefalites - São caracterizadas por paralisias de vários nervos cranianos, porém, não só elas costumam ser bilaterais, como a evolução se faz geralmente com caráter saltuário, e as lesões podem ser do tipo parcelado, nuclear. Entretanto, Garcin ${ }^{41}$ já citava os casos de Dercum e de Lévi, em que as paralisias se haviam mantido unilaterais, e, com Renard ${ }^{43}$, tratou especialmente do assunto, apresentando, entre vários casos de paralisias múltiplas periféricas de origem polioencefalitica, um em que a síndrome foi extensa e unilateral. Trelles e Lazarte ${ }^{127}$ registraram um caso de polioencefalite subaguda com paralisia unilateral dos nervos III a VIII.

Nem sempre o diagnóstico diferencial entre polioencefalite e tumor da base é simples: no caso de Monier-Vinard e Brunel ${ }^{81}$, em vista da normalidade das radiografias da base craniana, foi feito o diagnóstico de polioen- 
cefalite, mas a evolução ulterior e a necropsia revelaram que se tratava de fibrossarcoma basilar.

Tumores do tronco encefálico - Algumas vêzes, estas neoplasias, configurando uma síndrome paralítica múltipla de nervos cranianos, podem levar a diagnóstico errôneo. Assim, no caso de Assis e Maffei ${ }^{9}$, havia paralisia dos oito últimos nervos cranianos à esquerda (em associação com sinais vestibulocerebelares), determinada por um glioma do tronco cerebral.

Os granulomas (tuberculosos, luéticos, micóticos) podem eventualmente comportar-se como os tumores do tronco encefálico. Tal ocorreu no seguinte caso.

P.S., com 61 anos de idade, brasileiro, branco, internado na Clinica Neurológica em 26-4-1960 (reg. HC 583795). Há 3 meses começou a sentir dores de cabeça, de localização predominantemente parietal, com caráter contínuo. Um mês após, manifestou-se desvio da bôca para a esquerda, estabelecendo-se ulteriormente incapacidade de ocluir as pálpebras, à direita. Zumbidos e hipoacusia, à direita, também se fizeram notar desde o principio da doença. Há alguns dias, dificuldade para deglutir, especialmente os alimentos secos. Uiltimamente, dores violentas no território superior da hemiface direita. Exame clínico - Nada de particular em relação aos diversos aparelhos. Rinofaringe e otoscopia normais.

Exame neurológico - Equilibrio instável, observando-se retro e lateropulsões para a esquerda; a marcha realiza-se com dificuldade, notando-se tendencia a desvios para a esquerda. Nervos cranianos: Acentuada hiposmia à direita. Pupilas isocóricas e isocrômicas, com reflexos conservados. Paralisia do reto externo direito e dos músculos inervados pelo oculomotor à esquerda; fundos oculares normais. Hipoestesia acentuada e ulceração superficial da córnea direita. Paralisia facial, de tipo periférico, à direita; ageusia ipsolateral. Hipoacusia e arreflexia canalicular à excitação vestibular, do lado direito. Dêste mesmo lado, paralisia velofaringolaringea, com estase salivar no seio piriforme. A lingua se desvia para a direita, quando projetada fora da bôca; os movimentos de lateralização para a direita são limitados.

Exames complementares - Craniograma: ausência de sinais de hipertensão intracraniana e de lesão destrutiva dos ossos da calota ou da base. Liqüido cefalorraqueano (punção suboccipital): normal. Carótido-angiografia (direita): normal.

Evolução - O paciente passou a apresentar distúrbios respiratórios e, após a feitura de perfurações occipitais (preparatórias para a iodoventriculografia), houve agravação do estado geral, ocorrendo o óbito em 29-6-1960. Necropsia (SS 54380/60, Dr. Fernando S. Monteiro): Foi verificada a existência de lesão bulboprotuberancial, à direita, comprometendo os núcleos dos nervos encefálicos aí localizados. O exame histopatológico revelou tratar-se de granuloma, tendo sua parte central constituida por tecido necrótico; no mesmo foram encontradas formações com aspecto de levedura (coloração especifica pelo PAS e Gridley). Trata-se, pois, de granuloma micótico, provàvelmente causado por Monilia (a cultura, entretanto, não pôde ser realizada).

Meningites crônicas da base - Até há alguns anos, eram relativamente freqüentes os registros de casos de paralisias múltiplas de nervos cranianos, determinadas por meningites sifilíticas ou tuberculosas. As primeiras rece- 
beram mesmo, de Charcot, o nome de "tabes superior" e atingiriam particularmente a raiz motora do trigêmeo, os nervos motores oculares e o hipoglosso ${ }^{41}$. Geralmente, a paralisia é bilateral, mas há, na literatura, relatos de sindromes unilaterais. É necessário frisar, porém, que nem sempre o diagnóstico etiológico foi estabelecido com segurança (casos de Rose ${ }^{109}, 33$ de Garcin ${ }^{41}$, de Lortat-Jacob e Poumeau-Delille ${ }^{-1}$; casos de Mendel, de Rothmann, de Froment, Colrat e Dechaume, citados por Garcin ${ }^{41}$ ). Contudo, no caso de Rose e Lemaître ${ }^{110}$, além de paralisias oculares, havia francos sinais de tabes; no caso de Hausman ${ }^{50}$ havia alterações radiológicas da base sugestivas de osteíte luética (reação de Wassermann positiva no sangue, negativa no líquor). Num dos casos de Christiansen ${ }^{25}$ (paralisia unilateral dos nervos I, III, IV, V, VII, VIII e IX) podia falar-se com segurança em meningite luética, em vista dos resultados dos exames de líqüido cefalorraqueano e da positividade da reação de Wassermann no sangue. Em nosso meio, Lange e Silva $\mathrm{Jr}^{63}$ registraram um caso de meningite luética da base (modalidade Frankl-Hochwartz) com paralisia dos nervos III a VIII à direita, acompanhada de síndrome piramidal no hemicorpo esquerdo; a etiologia sifilitica foi firmada pelo exame do líqüido cefalorraqueano, bem como pela cura humoral e pela acentuada melhora clínica obtida com o tratamento especifico.

Quanto às paquimeningites tuberculosas, também numerosos casos com paralisias unilaterais de nervos cranianos foram relatados. Todavia, essa etiologia é discutível em muitos dêles (casos de Lortat-Jacob e Hallez io, Chatelin ${ }^{24}$, Jedlowski ${ }^{57}$ ).

Aneurismas de artérias encefálicas - Enquanto as paralisias dos nervos motores oculares constituem manifestações relativamente freqüentes nos aneurismas da porção anterior do circulo de Willis, os demais nervos só em raríssimas eventualidades vêm a ser comprometidos. A lesão dos nervos oculares pode ocorrer em conseqüência de dois mecanismos: compressão direta pelo saco aneurismático, levando a hemorragia intramural por obstrução venosa, cu em decorrência de hemorragia ocasionada pela rotura do aneurisma (Hyland e Barnett ${ }^{52}$ ). É óbvia, porém, a possibilidade de lesão de outros nervos, que não exclusivamente os motores oculares, em aneurismas situados em territórios vasculares mais caudais. Tal, por exemplo, o caso de Molinié ${ }^{79}$, caracterizado por paralisia unilateral dos seis últimos nervos cranianos, constituída no decurso de 25 anos.

A análise dos dados amnésticos e das manifestações objetivas, assessorada pelos atuais recursos da radiologia simples e contrastada, do exame do líquor completo e minucioso, bem como o auxílio valioso do exame neurotorrinolaringológico, possibilitam, na grande maioria das vêzes, o diagnóstico diferencial entre os tumores da base e as várias afecções aqui referidas. Convém, entretanto, ter em mente estas possibilidades, para que se possa fazer um juizo seguro ante os casos de paralisia múltipla de nervos cranianos. Verificada a normalidade do exame do líqüido cefalorraqueano e a 
harmonia das eventuais alterações vestibulares, essa síndrome neurológica, quando desacompanhada de sinais de lesão das vias sensitivas, motoras ou cerebelares e de hipertensão intracraniana, deve fazer pensar, inicialmente, em tumor da base do crânio, mesmo perante a normalidade do craniograma de rotina e até em presença de um exame negativo da rinofaringe.

\section{TRATAMENTO}

No tocante aos tumores nasofaríngeos, os autores mostram-se pessimistas quanto aos resultados do tratamento cirúrgico, visto que a natureza indiferenciada e a topografia dessas neoplasias, bem como a precoce ocorrência de metástases inabordáveis, não permitem geralmente a extirpação total. O mesmo podemos dizer das neoplasias primitivas da base do crânio, com exceção dos meningiomas.

A radioterapia profunda pelo método do fracionamento (Coutard ${ }^{31}$ ) possibilita a concentração de doses elevadíssimas no foco tumoral. Após o aparecimento desta técnica, em 1929, as estatísticas de sobrevida melhoraram sensivelmente, embora as cifras variem muito com os autores, o que, segundo Scevola ${ }^{114}$, se deve à diversidade de fase evolutiva em que o tratamento foi instituido.

$\mathrm{Na}$ indicação da radioterapia deve-se levar em conta o quadro histopatológico, a sede, o desenvolvimento, as condições dos tecidos adjacentes, as metástases regionais e à distância, a idade do paciente e as afecções concomitantes ${ }^{114}$. Simmons e Ariel ${ }^{119}$, Arana Íñiguez e col. ${ }^{6}$ e Molony 80 trataram pormenorizadamente da técnica da radioterapia convencional. Molony ${ }^{80}$, em 1957, preconizou o emprêgo da cobaltoterapia associada ao radium; de 4 casos assim tratados, 3 estavam vivos, um dêles apresentando sobrevida superior a 2 anos; o autor acredita que, com a aplicação dêsse método, já se poderá pensar em sobrevidas de 10 anos.

Em um dos casos de linfepitelioma, estudado por Aboab e col. ${ }^{1}$, o emprêgo da mostarda nitrogenada associada à radioterapia parece ter contribuido para a sensivel remissão notada no quadro clínico-neurológico.

A quimioterapia regional anticancerosa, ainda em fase de estudos, poderá eventualmente representar importante contribuição para a resolução dêste problema.

\section{PROGNÓSTICO}

O prognóstico depende da precocidade do diagnóstico e dos caracteres do tumor ${ }^{6}$, tais como natureza histológica, aspecto macroscópico, localização, extensão local, presença de metástases ganglicnares e condições gerais do paciente. 
As cifras de sobrevida de 5 anos são muito variáveis (de 6,2 a 25,0\%) e não guardam relação com o período cronológico em que foram calculadas $44,58,74,80,85,119,138$. Godtfredsen ${ }^{44}$ comparou a sobrevida de 5 anos em 270 casos de carcinoma $(3,7 \%)$ e 270 de sarcomas $(19,2 \%)$ recolhidos na literatura, o que significa que o prognóstico é cinco vêzes melhor nestes últimos.

Nos 128 casos de óbito do material de Simmons e Ariel ${ }^{119}$, a duração média após os primeiros sintomas foi de 27 meses; em 7 pacientes não tratados a sobrevida foi de 17 meses; em 89 pacientes mortos após terem feito radioterapia, a sobrevida foi de 31 meses. Os melhores resultados foram consignados em pacientes de 30 a 40 anos; os mais idosos apresentaram a menor cifra de sobrevida. Foram obtidas curas em alguns casos com metástases ganglionares unilaterais, o que não aconteceu em nenhum dos casos com metástases bilaterais.

Por outro lado, na série de Simmons e Ariel ${ }^{119}$, nenhum paciente com lesões de nervos cranianos atingiu a sobrevida de 5 anos. No material de Riggs e col.102, mais da metade dos pacientes faleceu dentro de 10 meses após o aparecimento de sinais neurológicos.

\section{RESUMO}

São apresentadas as observaçōes de 9 pacientes, cuja sintomatologia neurológica era circunscrita aos territórios dependentes de nervos cranianos, acometidos de maneira múltipla e, na quase totalidade dos casos, unilateralmente. Distúrbios neurológicos nos membros e sinais de hipertensão intracraniana não existiam. Pronunciadas alterações radiológicas da base do crânio, especialmente localizadas na fossa média, foram evidenciadas em 7 casos. Quatro das observações enquadram-se na sindrome de Garcin, a paralisia comprometendo globalmente os nervos cranianos de um mesmo lado; nas demais observações ocorreram paralisias associadas de determinados nervos, geralmente os do andar médio do crânio.

Em face do quadro clínico observado, o diagnóstico de tumor da base craniana pôde ser estabelecido, apurando-se, em quatro casos, a origem rinofaringea da neoplasia. Quanto à natureza do tumor, exames histopatológicos demonstraram tratar-se, em 5 casos, de carcinoma e, em 3, de sarcoma; no caso restante, tratava-se de tumor glômico.

É ainda apresentada a observação de um paciente no qual a sintomatologia se limitava também, pràticamente, à paralisia múltipla de nervos cranianos, e no qual o diagnóstico diferencial entre tumor basilar e neoplasia do tronco encefálico foi especialmente discutido; o exame necroscópico positivou a última hipótese, revelando tratar-se de um granuloma micótico da ponte.

A propósito dos casos relatados, os autores fazem revisão do assunto, considerando o histórico, natureza, sintomatologia, diagnóstico, diagnóstico diferencial, tratamento e prognóstico dos processos tumorais da base do crânio. 


\section{SUMMARY \\ Multiple unilateral paralysis of the cranial nerves produced by tumors of the skull basis.}

The authors report the cases of 9 patients whose neurological symptoms were limited to the areas innervated by the cranial nerves, which were affected in a multiple way and, in almost all of the cases, unilaterally. There were neither signs of increased intracranial pressure nor of neurological involvement of other areas not innervated by the cranial nerves. Severe roentgenological alterations of the skull basis, specially located in the middle cranial fossa, were evidenced in 7 cases. Four cases fit the Garcin's syndrome, for the paralysis involved all of the cranial nerves in one side; in the other cases there were associated paralysis of several nerves, generally those of the middle cranial fossa.

In view of the clinical picture the diagnosis of tumor of the skull basis could be made, and in 4 of the cases the nasopharyngeal origin of the neoplasm was verified. As to the nature of the tumor, histopathological studies showed that 5 were epitheliomas, 3 were sarcomas, and 1 was a glomus tumor.

The authors also report a case in which the symptoms were restricted to multiple paralysis of cranial nerves, the differential diagnosis between tumor of the skull basis and neoplasm of the brain stem being particularly discussed; the post mortem study confirmed the last hypothesis, showing a mycotic granuloma of the pons.

In connection with the cases reported, the authors make a review of the subject, considering the history, nature, symptoms, diagnosis, differential diagnosis, treatment and prognosis of the tumoral conditions of the skull basis.

\section{REFERENCIAS}

1. ABOAB, R. B.; SCHERMANN, J.; BARRETTO Netto, M. - Tumores malignos do cavum. Arq. Bras. Med., 44:87-112 (março-abril) 1954. 2. ALEXANDER Jr., E.; BEAMER, P. R.; WILliAMS, J. O. - Tumor of the glomus jugulare with extension into the middle ear (nonchromaffin paraganglioma or carotid-body-type tumor). J. Neurosurg., 8:515-522 (setembro) 1951. 3. ANDRÉ, M.-J. - Paralysie unilatérale des nerfs craniens par tumeur de la base, avec hypertrophie facio-linguale homolatérale. J. Belge Neurol. Psychiat., 47:115-118 (fevereiro) 1947. 4. ANDRE-THOMAS - Paralysie unilatérale des six derniers nerfs craniens. Méningiome de la fosse cérébelleuse. Presse Méd., 45:1785-1786 (11 dezemtro) 1937. 5. APRIGLIANO, F. - Um caso de paralisia unilateral global dos nervos cranianos (síndrome de Garcin). Rev. Bras. Otorrinolaring., 15:23-32 (janeiro-fevereiro) 1947. 6. ARANA IÑIGUEZ, R.; CAUBARRERE, N.; KASDORF, H. - Síntomas neurológicos de los tumores del cavum. An. Inst. Neurol,, Montevidéu, 11/2:33-60, 1955-56. 7. ASENJO, A.; LEA-PLAZA, H.; ARANGO, A. J. - El sindrome de parálisis unilateral global de los nervios craneanos. Rev. Fac. Med., Bogotá, 16:943-950 (outubro) 1947. 8. ASENJO, A.; ROCA, E. D. - Compromiso de los pares craneanos en la cisticercosis cerebral. Rev. Méd. Chile, 74:605-615 (setembro) 1946. 9. ASSIS, J. L.; MAFFEI, W. E. - Síndrome dos nervos cranianos por glioma do tronco cerebral. Estudo 
anátomo-clínico de um caso. Arq. Neuro-Psiquiat., 3:61-67 (março) 1945.10. BAASCH, E. - Contribution à l'étude du "syndrome paralytique unilatéral global des nerfs craniens " (syndrome de R. Garcin). Schweiz. Arch. Neurol. Psychiat., 63:5-16, 1949. 11. BABONNEIX, L.; SIGWALD, J. - Syndromes paralytiques progressifs des nerfs craniens par tumeurs basilaires. Gaz. Hôp., 102:15€̣5-1509 (23 outubro) 1929. 12. BALLENGER, H. C. - Carcinoma of nasopharynx with destruction of cranial nerves, including second and eighth nerves. Ann. Otol., 42:899-902 (setembro) 1933. 13. BARTELS, J. - De Tumoren van het Glomus jugulare. Tese, Universidade de Groningen, 1949. Cit. por Henson e col.51. 14. BERTOLOTTI, M. - Studio radiologico dei tumori craniofaringei. Arch. Ital. Chir., 12:621-652, 1925. 15. BOCCIA, D.; RIZZO, J. - Tumores nasofaringeos y sindromes paraliticos de nervios craneanos. Prensa Méd. Argent., 23:2723-2730 (9 dezembro) 1936.16. BONNAHON, D. - Les syndromes paralytiques des nerfs craniens. Rev. Laryng. (Bordeaux) 53:595-644 (maio) 1932. 17. BONNE, C. - Cancer and human race. Am. J. Cancer, 30:435-454 (julho) 1937. 18. BROCK, S. - Symposium on nasopharyngeal tumors. III: From the neurological viewpoint. Laryngoscope, 51:455457 (maio) 1941. 19. CAMAUER, A. F.; SACON, J. I. - Parálisis unilateral global de los nervios de la base del cráneo por cordoma de la sincondrosis fisalifora (sindrome de Guillain y Garcin). Rev. A. Méd. Argent., 48:1251-1255 (novembro) 1934. 20. CANELAS, H. M.; CRUZ, O. R.; TENUTO, R. A. - Tumores congênitos do sistema nervoso. I: Cistos epidermóides e dermóides. Arq. Neuro-Psiquiat., 18: 209-223 (setembro) 1960. 21. CANELAS, H. M.; CRUZ, O. R.; TENUTO, R. A.; CURY, L. - Tumores congênitos do sistema nervoso. II: Craniofaringiomas. Arq. Neuro-Psiquiat., 19:79-100 (junho) 1961. 22. CARREA, R. M. E.; INSAUSTI, T. Angiomas originados en el oido medio. Arch. Neurocir., 1:67-82 (janeiro-março) 1944. 23. CHARLEUX; MOUNIER-KUHN; FEUILLADE; GIRARD; LEVY, A. - Sur une observation de paralysie unilatérale des nerfs craniens par epithélioma tubaire. Lyon Méd., 155:399-403, 1935. 24. CHATELIN, C. - Paralysies multiples unilatérales des nerfs craniens. Rev. Neurol., 26:784-786, 1913. 25. CHRISTIANSEN, V. - Les Tumeurs du Cerveau, 2a ed. Masson, Paris, 1925, págs. 163-165. 26. CLARK, O. - Paralisia unilateral dos doze pares craneanos. Bol. Acad. Nac. Med., 100: 852-853 (7 novembro) 1929. 27. CLARKE, E. - Cranial and intracranial myeloma. Brain, 77:61-81 (marco) 1954. 28. COLLET, F. J. - Sur un nouveau syndrome paralytique pharyngo-laryngé par blessure de guerre. Hémiplégie glosso-laryngoscapulo-pharyngée. Lyon Méd., 124:121-129 (abril) 1915. 29. CORNIL, L.; HENNEQUIN; KISSEL, P. - Paralysie globale des nerfs moteurs de l'œil (œil de poupée) par fracture isolée du 1/3 interne du rocher. Paris Méd., 20:135-138 (9 agôsto) 1930. 30. COULLIAUD-MAISONNEUVE, G.; MONDZAIN, M.-L. — Association d'un syndrome de Trotter et d'un syndrome de Guillain et Garcin au cours d'un epithélioma du cavum. Rev. d'Oto-Neuro-Ophtalmol., 28:446-447, 1956. 31. COUTARD, H. - Zusammenfassung der Grundlage der röntgentherapeutischen Technik der tiefgelegen Krebse. Strahlentherapie, 37:50-58, 1930. Cit. por Godtfredsen ${ }^{44}$. 32. CRUZ, O. R.; TENUTO, R. A. - Meningeomas: acometimento isolado de nervos cranianos. Arq. Neuro-Psiquiat., 17:398-405 (dezembro) 1959. 33. DrGBY, K. H.; FOOK, W. L.; CHE, Y. T. - Nasopharyngeal carcinoma. Brit. J. Surg., 28:517-537 (abril) 1941. 34. DUCUING, J.; DUCUING, L. - Les tumeurs malignes du nasopharynx. Rev. Laryng. (Bordeaux) 54:1213-1266, 1933. 35. DURAND-FARDEL - Cancer du pharynx. Bull. Soc. d'Anat., 12:73-80, 1837. Cit. por Jackson ${ }^{54}$. 36. ESCAT, E. - Maladies du Pharynx. Paris, 1901. Cit. por Godtfredsen ${ }^{44}$. 37. FrNZI, A. - Fall von Tumor des Nasenrachenraumes mit Metastasen an der Gehirnbasis und im Rückenmark. Mitt. Gesellsch. inn. Med. u. Kinderh. in Wien, 13:161-163, 1914. Cit. por Woltman ${ }^{136}$, 38. FLOUR - Considérations sur les tumeurs de la voûte pharyngienne. Tese, Paris, 1873. Cit. por Godtfredsen ${ }^{44}$. 39. FOIX, Ch. - Syndrome de la paroi externe du sinus caverneux. Bull. Mém. Soc. Méd. Hôp. Paris, 44:1355-1361 (12 novembro) 1920. 40. FURSTENBERG, A. C. - Malignant neoplasms of the nasopharynx. Surg., Gynec. Obst., 66:400-404 (15 fevereiro) 1938. 41. GARCIN, R. Le syndrome paralytique unilatéral global des nerfs craniens. Contribution à l'étude des tumeurs de la base du crâne. A. Legrand, Paris, 1927. 42. GARCIN, R.; FISCH- 
GOLD, H.; GODLEWSKI, St. - Les formes neurologiques des tumeurs du glomus jugulaire (à propos de trois observations). Rev. Neurol., 103:557-558 (dezembro) 1960. 43. GARCIN, R.; RENARD, G. - Sur quelques cas de paralysies multiples, extensives et curables, des nerfs craniens. Polioencéphalite subaiguë à virus neurotrope probable. Paris Méd., 2:263-272 (6 outubro) 1934. 44. GODTFREDSEN, E. - Ophthalmologic and neurologic symptoms at malignant nasopharyngeal tumours. A clinical study comprising 454 cases. Acta Oto-Laryng., supl. 59, 1944. 45. GOTOR, P. - Parálisis unilateral de los nervios craneales (sindrome de Garcin). Rev. Neurol. Clín. (Madrid) 1:7-11 (dezembro) 1953. 46. GRADENIGO, G. - Sur un syndrome particulier de complications endocraniennes otitiques: paralysie de l'abducteur d'origine otitique. Ann. Mal. Oreille, 30:120-152, 1904. Cit. por Godtfredsen ${ }^{44}$. 47. GUILlaIN, G.; ALAJOUANINE, T.; GARCIN, R. - Le syndrome paralytique unilatéral global des nerfs craniens. Bull. Mém. Soc. Méd. Hôp. Paris, 42: 456-460 (19 março) 1926. 48. GUILLAIN, G.; GARCIN, R.; JONESCO - Syndrome paralytique unilatéral global des nerfs craniens par métastase sur la base du crâne d'un epithélioma du sein. J. Belge Neurol. Psychiat., 29:268-271 (maio) 1929. 49. HARTMANN, F. - Beiträge zur pathologischen Anatomie und Klinik der Geschwülste der Schädelbasis. J. Psychiat. Neurol., 6:209, 1905-1906. Cit. por Garcin ${ }^{41} .50$. HAUSMAN, I. - Syndrome d'une hémiparésie des nerfs craniens par inflammation syphilitique des os de la base du crâne. Schweiz. Arch. Psychiat. Neurol., 62:396397, 1948. 51. HENSON, R. A.; CRAWFORD, J. V.; CAVANAUGH, J. B. - Tumours of the glomus jugulare. J. Neurol. Neurosurg. Psychiat., 16:127-138, 1953. 52. HYLAND, H. H.; BARNETT, H. J. M. - The pathogenesis of cranial nerve palsies associated with intracranial aneurysms. Proc. Roy. Soc. Med., Sect. Neurol., 47: 141-146 (fevereiro) 1954. 53. INSAUSTI, T.; MUSACCHIO, J. M.; ZAMBONI, M. Tumores malignos del cavum. Síntomas neurológicos, diagnóstico precoz. Rev. Neurol. Buenos Aires, 16:75-108 (abril-julho) 1958. 54. JACKSON, C. - Primary carcincma of the nasopharynx. A table of cases. J.A.M.A., 37:371-377 (10 agôsto) 1901. 55. JACKSON, Harry - Craniopharyngeal duct tumors. J.A.M.A., 66:10821084 ( 8 abril) 1916. 56. JACOD, M. - Sur la propagation intracranienne des sarcomes de la trompe d'Eustache. Syndrome du carrefour patrosphenoïdal. Paralysie des 2e, 3e, 4e, 5e et $6 e$ paires craniennes. Rev. Neurol., 37:33-38 (janeiro) 1921. 57. JEDLOWSKI, P. - Sindrome paralitica unilaterale globale dei nervi cranici da pachimeningite tuberculare. Giorn. Psichiat. Neuropatol., 70:141-176, 1942. 58. KASABACH, H. H. - Roentgenography of the malignant nasopharyngeal tumors. A preliminary report. Laryngoscope, 51:459-463 (maio) 1941. 59. KLEINFELD, L. Malignancies of the nasopharynx. Laryngoscope, 46:415-418, 1936. 60. KOJEVNIKOFF, A. - Les paralysies unilatérales de tous les nerfs craniens. Rev. Neurol., 50:693-699 (novembro) 1928. 61. KRAYENBUHL, H.; RICHTER, H. R. - Die zerebrale Angiographie. Thieme, Stuttgart, 1952, págs. 52-53. 62. LAFON, R.; PAGES, P.; CAZABAN, R.; LABAUGE, R.; ABRIC, J. - Syndrome de Garcin incomplet d'origine hodgkinienne. Rev. d'Oto-Neuro-Ophtalmol., 28:230-231, 1956. 63. LANGE, O.; SILvA Jr., J. A. C. - Meningite luética da base com polinevrite de nervos cranianos: modalidade Frankl-Hochwartz. São Paulo Méd., 5:171-184 (fevereiro) 1941. 64. LATTES, R.; WALTNER, J. G. - Nonchromaffin paraganglioma of the middle ear. Cancer, 2:447-468 (maio) 1949. 65. LAVAL, F. - Des tumeurs malignes $\mathrm{du}$ nasopharynx. Tese, Toulouse, 1904. Cit. por Godtfredsen ${ }^{44}$. 66. LECHELLE, P.; MIGNOT, H.; PERROT; VINCENT - a) Paralysie partielle unilatérale des nerfs craniens, vraisemblablement consécutive à des métastases d'epithéliomas cutanés. Bull. Mém. Soc. Méd. Hôp. Paris, 53:639-643 (7 maio) 1937. b) Paralysie partielle unilatérale des nerfs craniens, vraisemblablement consécutive à des métastases d'epithéliomas cutanés. Action favorable de la radiothérapie. Bull. Mém. Soc. Méd. Hôp. Paris, 53:903-905 (11 junho) 1937. 67. LEPOIRE, J.; PERTUISET, B. - Les Kystes Epidermoïdes Cranio-Encéphaliques. Masson, Paris, 1957. 68. LINCK, A. Chordoma malignum. Beitr. path. Anat., 46:573-585, 1909. Cit. por Garcin ${ }^{41}$. 69. LORENTE, R. A.; GARCIA, J. M. - Neuraxitis ectotropas y tumores endocraneanos (a propósito de un caso de tumor de Garcin). Arch. Histol. Norm. Patol., 3:345364 (novembro) 1946. 70. LORTAT-JACOB; HALLEZ, G. L. - Syndrome paraly- 
tique des six derniers nerfs craniens droits par adénopathie cervicale et pachyméningite tuberculeuse. Rev. Neurol., 34:513-516 (maio-junho) 1918. 71. LORTATJACOB; POUMEAU-DELILLE - Syndrome paralytique unilatéral partiel des nerfs craniens. Rev. Neurol., 49:565-568 (abril) 1928. 72. MAFFEI, W. E. - Tumores glômicos em otorrinolaringologia: anatomia patológica. Arq. Hosp. Santa Casa São Paulo, 5:11-22, 1959. 73. MARTIN, C. L. - Complications produced by malignant tumors of the nasopharynx. Am. J. Roentgenol., 41:377-390 (marco) 1939. 74. MARTIN, H. E.; BLADY, J. V, - Cancer of the nasopharynx. AMA Arch. Otolaryng., 32:692-727 (outubro) 1940. 75. MARTINEZ, J.; LEVIT, L. - Paralisia unilateral global de los nervios craneales. Rev. Méd, Rosario, 33:19-23 (janeiro) 1943.76. McWHIRTER, R. - Early diagnosis of nasopharyngeal carcinoma. Proc. Roy. Soc. Med., 46:821-823 (outubro) 1953. 77. MEKIE, D. E. C.; LAWLEY, M. - Nasopharyngeal carcinoma. I: Clinical analysis of one hundred twenty cases. AMA Arch. Surg., 69:841-848 (dezembro) 1954. 78. MELLO Filho, G. - Síndrome paralitica dos seis últimos nervos cranianos. Arq. Inst. Penido Burnier, 3:78-83 (março) 1934. 79. MOLINIÉ - Paralysie unilatérale des six derniers nerfs craniens par tumeur anévrysmale. Rev. Neurol., 45:1272 (junho) 1926. 80. MOLONY, T. J. Malignant tumors of the naso-pharynx. Laryngoscope, 67:1297-1305 (dezembro) 1957. 81. MONIER-VINARD; BRUNEL, M. - a) Polioencéphalite subaiguë du tronc cérébral. Atteinte unilatérale de dix paires craniennes. Rev. Neurol, 66:62-67 (julho) 1936. b) Paralysie unilatérale de dix paires craniennes. Syndrome de Garcin. Rev. Neurol., 67:221-224 (fevereiro) 1937. 82. MONTANARO, J. C.; FRANCHINI, Y.; BLOTTA, F. - Síndrome paralítico unilateral global de los nervios craneanos (de Guillain, Alajouanine y Garcin) por neoplasia basílar. Semana Méd., 50:1118-1123 (11 novembro) 1943. 83. MOUNIER-KUHN, P. — Syndrome des quatre derniers nerfs craniens d'origine neoplasique probable. Lyon Méd., 151:77-80 (15 janeiro) 1933. 84. NEEDLES, W. - Malignant tumors of the nasopharynx (with special reference to the neurological complications). J. Nerv. Ment. Dis., 86:373-398 (outubro) 1937. 85. NEW, G. B. - a) Syndrome of malignant tumors of the nasopharynx: a report of 79 cases. J.A.M.A., 79:10-14 (1 julho) 1922 . b) The treatment of malignant tumors of the pharynx and nasopharynx. Surg. Gynec. Obst. 40:177182 (fevereiro) 1925. 86. NEW, G. B.; BRODERS, A. C.; CHILDREY, S. H. Highly malignant tumors of the pharynx and base of the tongue. Surg. Gynec. Obst., 54:164-174 (fevereiro) 1932. 87. NIELSEN, J. - Roentgen treatment of malignant tumors of the nasopharynx. Acta Radiol., 26:133-154, 1945 . 88. OPPIKOFER, E. - Uber die primäre maligne Geschwülste des Nasenrachenraumes. Arch. f. Laryng. u. Rhin., 27:526-564, 1913. 89. ORBAN, T. - Neurologische Syndrome bei bösartigen Geschwülste des Rhinopharynx. Confinia Neurol., 17:231-242, 1957.90. OSORIO, L. A. - Estudo clinico da sindrome paralitica unilateral dos nervos cranianos (sindrome de Garcin incompleta). Rev. Med. Rio Grande do Sul, 3:135-138 (janeiro-fevereiro) 1947. 91. OYA, J. C.; SEGOVIA, J. M. - El síndrome neurológico de los tumores del cavum. Rev. Clín. Españ., 46:143-150 (15 agôsto) 1952. 92. PACHANTONI - Paralysies multiples des nerfs craniens par "vent d'obus". Rev. Méd. Suisse Romande, 37:226 (abril) 1917. Resumo in Rev. Neurol., 32:369 (junho) 1917. 93. PACK, G. T. - Unilateral neurofibromatosis of the cranial and deep cervical nerves. AMA Arch. Neurol. Psychiat., 21:919-923 (abril) 1929. 94. PAGNIEZ, Ph.; DECOURT, Th.; PLICHET, A. - Syndrome paralytique unilatéral global des nerfs craniens d'origine traumatique. Rev. Neurol., 55:450-452 (abril) 1931.95. PARDAL, R. - Sindrome de Garcin: parálisis unilateral global de los nervios craneanos. Prensa Méd. Argent., 20:1520-1527 (12 julho) 1933. 96. PASTINE Paralysies multiples des nerfs craniens par éclatement d'obus sans blessure extérieure. Riv. Patol. Nerv. Ment., 23:1-9 (janeiro) 1918. Resumo in Rev. Neurol. 34: 233 (novembro-dezembro) 1918. 97. PAVIOT, J.; MOUNIER-KUHN; GUICHARD, A.; LEVY; LORAS - Sur un cas de paralysies multiples des nerfs craniens avec lesions osseuses radiologiques de la base du crâne. Lyon Méd., 155:418-422 (7 abril) 1935. 98. POPPEN, J. L.; RIEMENSCHNEIDER, P. A. - Tumors of the carotid body type presumably arising of the glomus jugularis. AMA Arch. Otolaryng., 53: 453-459 (abril) 1951. 99. REZENDE BARBOSA, J. E.; BASTOS, H.; DIAS, M. C. S.; 
MAFFEI, W. E. - Tumores glômicos em otorrinolaringologia. Arq. Hosp. Santa Casa São Paulo, 5:1-10, 1959. 100. RIEMENSCHNEIDER, P. A.; HOOPLE, G. S.; BREWER, D.; JONES, D.; ECKER, A. - Roentgenographic diagnosis of the glomus jugularis tumors. Am. J. Roentgenol., 69:59-65 (janeiro) 1953. 101. RIGAUD, P.; SENDRAIL, Th. - Paralysie multiple des nerfs craniens par un epithélioma basilaire. Syndrome de la face endocranienne du rocher et du trou dechiré postérieur. Ann. Mal. Oreille, 42:997-1003 (outubro) 1923. 102. RIGGS, H. E.; RUPP, C.; RAY, H.; YASKIN, J. C. - Cranial nerve syndromes associated with nasopharyngeal malignancy. AMA Arch. Neurol. Psychiat., 77:473-482 (maio) 1957. 103. ROGER, H. - Le syndrome paralytique unilatéral des six derniers nerfs craniens. Les tumeurs du glomus jugulaire. Rev. d'Oto-Neuro-Ophthalmol., 26:65-83, 1954.104. ROGER, H.; AYMES, G.; REBOULD-LACHAUX, J. - Paralysies multiples bilatérales des derniers nerfs craniens par lesion de l'étage moyen de la base du crâne. Marseille Méd., 58:1074-1080 (1 dezembro) 1921. Resumo in Rev. Neurol., 39:547 (maio) 1923. 105. ROGER, H.; MASINI, P.; POURSINES, Y. - Paralysie des six derniers nerfs craniens et $d u \mathrm{~V}$ gauche par tumeur névique du conduit auditif à marche très lente. Rev. d'Oto-Neuro-Ophthalmol., 8:136-138 (fevereiro) 1930. 106. ROGER, H.; PAILlAS, J. - Les paralysies multiples des nerfs craniens par propagation à la base des tumeurs rhino-pharyngées. Rev. d'Oto-Neuro-Ophthalmol., 13:165-185 (marco) 1935. 107. ROLLET, E. - Le syndrome de la fente sphenoïdale. J. Méd. Lyon, 8:127-133, 1927. 108. ROMAY, R. S.; BLUMTRITT, C. - Síndromes paralíticos múltiples unilaterales de los pares craneanos. Semana Méd., 48:181-188 (23 janeiro) 1941. 109. ROSE, F. - Paralysie des nerfs craniens d'un côté et déformations osseuses multiples d'origine probablement hérédo-syphilitique tardive. Nouvelle Iconogr. Salpêtrière, 17:277-282, 1904. 110. ROSE, F.; LEMAITTRE, F. - Méningite cranienne spécifique. Tabès? Rev. Neurol., 16:1340-1343 (dezembro) 1908. 111. ROSENBAUM, H. E.; SEAMAN, W. B. - Neurologic manifestations of nasopharyngeal tumors. Neurology, 5:868-874, 1955. 112. ROZSfVAL, V.; SCHROTTENBAUM, M. Supraselárni karcinom a klickym obrazem sarkomu lebni báse (Resumo em inglês: Suprasellar carcinoma imitating sarcoma of the base of the skull). Ceskoslov. Neurol., 24:126-130, 1961. 113. SALINGER, S.; PEARLMAN, S. J. - Malignant tumors of the epipharynx. AMA Arch. Otolaryng., 23:149-172 (fevereiro) 1936. 114. SCEVOLA, P. - Le neoplasie del rinofaringe. Studio anatomopatologico, clinico e radiologico. Arch. Ital. Otol., 60, supl. 2, 1949. 115. SCHWEICH - Tumeur fibroplastique de la base du crâne. Bull. Soc. d'Anat. Paris, 42:256-261, 1867. Cit. por Godtíredsen ${ }^{44}$. 116. SICARD, J. A. - Syndrome du carrefour condylo-déchiré (type pur de paralysie des quatre derniers nerfs craniens). Bull. Mém. Soc. Méd. Hôp. Paris, 33:317-327 (22 fevereiro) 1917. 117. SICHEL, D.; WILD, Ch.; KLOTZ, G.; VOEGTLIN - Radiographies et tomographies de tumeurs du cavum. J. Radiol. Électrol., 38:760-762, 1957. 118. SILVA, L.; DUARTE, I.; TAVARES, C. L.; ELEJALDE, P. - Contribuição ao estudo anátomo-clínico do síndrome paralítico unilateral global dos nervos cranianos (síndrome de Garcin). An. Fac. Med. Univ. Minas Gerais, 2:19-48, 1930. 119. SIMMONS, M. W.; ARIEL, I. M. - Carcinoma of the nasopharynx. Report of 150 cases. Surg. Gynec. Obst., 88:763-775 (junho) 1949. 120. SOUCY, G. - Contribution à l'étude des tumeurs malignes primitives du nasopharynx. Tese, Argel, 1911. Cit. por Godtfredsen ${ }^{44}$. 121. SPARLING Jr., H. J.; ADAMS, R. D.; PARKER Jr., F. - Involvement of the nervous system by malignant lymphoma. Medicine, 26:285-332 (setembro) 1947. 122. STAFFIERI, D.; MINNHAAR, T. C.; LEVIT, L. - Sindrome paralítico unilateral global de los nervios craneales, aparecido en una enferma portadora de un linfogranuloma maligno. Rev. Méd. Rosario, 31:485-502 (junho) 1941. 123. TINEL, J.; FOURESTIER, M.; FRIEDMAN, E. - Tumeur cranio-pharyngée (chordome) avec paralysies multiples des nerfs craniens. Rev. Neurol., 63:583-589 (abril) 1935. 124. TOLEDO, P. A.; GAMA, C. Estudo clínico-radiológico dos tumores da região craniofaringea. Rev. Oto-Laring. São Paulo, 6:1-28 (maio-junho) 1938. 125. TOLOSA, E. - Angiografia Cerebral. Paz Montalvo, Madrid, 1953. 126. TRELlES, J. O. - Cisticercosis racemosa. Rev. Neuro-Psiquiat., 5:573 (dezembro) 1942. 127. TRELLES, J. O.; LAZARTE, J. J. Polioencefalitis subaguda. Rev. Neuro-Psiquiat., 7:265-269 (junho) 1944. 128. TROT- 
TER, W. - Symptoms of malignant tumours of the naso-pharynx. Lancet, i:1277 (13 maio) 1911. 129. VERNET, M. - Le syndrome du trou déchiré postérieur. Paris Méd., 7:78 (27 janeiro) 1917. 130. VILlaRET, M. - Le syndrome de l'espace rétro-parotidien postérieur. Paris Méd., 7:430 (26 maio) 1917. 131. VOTO-BERNALES, J.; JIMENEZ, J.; DELGADO P., J. - Sindrome de Garcin por tumor mixto parotideo. Rev. Neuro-Psiquiat., 7:269-271 (junho) 1944. 132. WEISS, H. - Halbbasissyndrom (Syndrom Garcin) bei Glomustumoren (nichtchromaffine Paragangliome) des Mittelohres. Nervenarzt, 26:289-291, 1955. 133. WICKBOM, I. - Angiography of the carotid artery. Acta Radiol., supl. 72, 1948. 134. WINSHIP, P.; KLOPP, V. T.; JENKINS, W. H. - Glomus-jugularis tumors. Cancer, 1:441-448 (setembro) 1948. 135. WINTER, P.; GARCIN, R.; DEREUX, J. - Paralysies multiples unilatérales des nerfs craniens. Bull. Mém. Soc. Méd. Hôp. Paris, 50:1553-1556 (11 novembro) 1926. 136. WOLTMAN, H. W. - Malignant tumors of the nasopharynx with involvement of the nervous system. AMA Arch. Neurol. Psychiat., 8:412-429 (outubro) 1922. 137. WORMS, G.; CARILlON, R. - Tumeurs du rhinopharynx à propagation cranienne. De leur diagnostic précoce; importance de l'examen radiologique. Rev. d'Oto-Neuro-Ophthalmol., 8:161-177 (março) 1930. 138. ZUPPINGER, A. - Archiv und Atlas der normalen und pathologischen Anatomie in typischen Röntgenbildern. Maligne Pharynx- und Larynxtumoren. Thieme, Leipzig, 1931. Cit. por Godtfredsen ${ }^{44}$.

Clínica Neurológica - Hospital das Clínicas da Fac. Med. da Univ. de São Paulo - Caixa Postal 3461 - Sũo Paulo, Brasil. 